\section{DAUER}

An arrested stage in

Caenorhabditis elegans

development that can be formed

in conditions of starvation or

overcrowding.
Department of Microbiology and Immunology, Stanford University School of Medicine, Stanford, California 94305, USA. Correspondence to K.K. e-mail: karlak@stanford.edu doi:10.1038/nrmicro865

\title{
CELLULAR AUTOPHAGY: SURRENDER, AVOIDANCE AND SUBVERSION BY MICROORGANISMS
}

\section{Karla Kirkegaard, Matthew P. Taylor and William T. Jackson}

Intracellular bacteria and viruses must survive the vigorous antimicrobial responses of their hosts to replicate successfully. The cellular process of autophagy - in which compartments bound by double membranes engulf portions of the cytosol and then mature to degrade their cytoplasmic contents - is likely to be one such host-cell response. Several lines of evidence show that both bacteria and viruses are vulnerable to autophagic destruction and that successful pathogens have evolved strategies to avoid autophagy, or to actively subvert its components, to promote their own replication. The molecular mechanisms of the avoidance and subversion of autophagy by microorganisms will be the subject of much future research, not only to study their roles in the replication of these microorganisms, but also because they will provide - as bacteria and viruses so often have - unique tools to study the cellular process itself.

Cellular autophagy involves the sequestration of regions of the cytosol within double-membrane-bound compartments that then mature and degrade their cytoplasmic contents. It is a highly regulated process, the components of which have only recently been identified by extensive studies using yeast genetics. Owing to groundbreaking work in Saccharomyces cerevisiae, a host of autophagy genes have now been described, the mechanisms of action of many of their products determined and their mammalian and other homologues identified ${ }^{1}$. In this review, we will use the notation $A T G$, the newly adopted nomenclature, for the genes that function in autophagy ${ }^{2}$. There is a substantial body of literature describing studies in which new genetic tools have been used to show that autophagy, its machinery or both are required for many aspects of cellular function and organismal development. For example, human beclin1, a homologue of yeast ATG6, has been shown to be a tumour-suppressor gene ${ }^{3}$. Starvation responses also require autophagy: DAUER formation in Caenorhabditis elegans requires functional beclin 1 (REF. 4) and the survival of Dictyostelium discoideum during nitrogen starvation requires functional homologues of yeast ATG5 and ATG7 (REF. 5). Furthermore, in both Arabidopsis thaliana ${ }^{6,7}$ and C. elegans ${ }^{4}$, wild-type autophagy genes are required to prevent premature senescence.

One attractive hypothesis is that the degradation of cytosolic structures by autophagy might have a general role in 'clearing away' intracellular pathogens. Observations of intracellular viruses and bacteria within multivesicular bodies have often been reported from electron-microscopy (EM) studies ${ }^{8}$. In addition, an unexplained phenomenon known as hepatic 'purging' is seen in hepatitis-B-infected chimpanzees. As many as $75 \%$ of the hepatic cells in these infected animals were shown to contain viral proteins at 10 weeks postinfection, but proved to be virus-free, in the absence of extensive cell death, by 20 weeks ${ }^{9}$. There must, therefore, be extremely efficient antimicrobial mechanisms that do not involve apoptosis or the destruction of infected hepatic cells by the immune system. In this review, we will discuss the accumulated functional evidence that autophagy is a component of the innate immune response that has both antiviral and antibacterial functions. Although this review will focus on viruses and intracellular bacteria, several reports have also indicated interactions between eukaryotic parasites and components of the autophagic pathway ${ }^{10,11}$. 

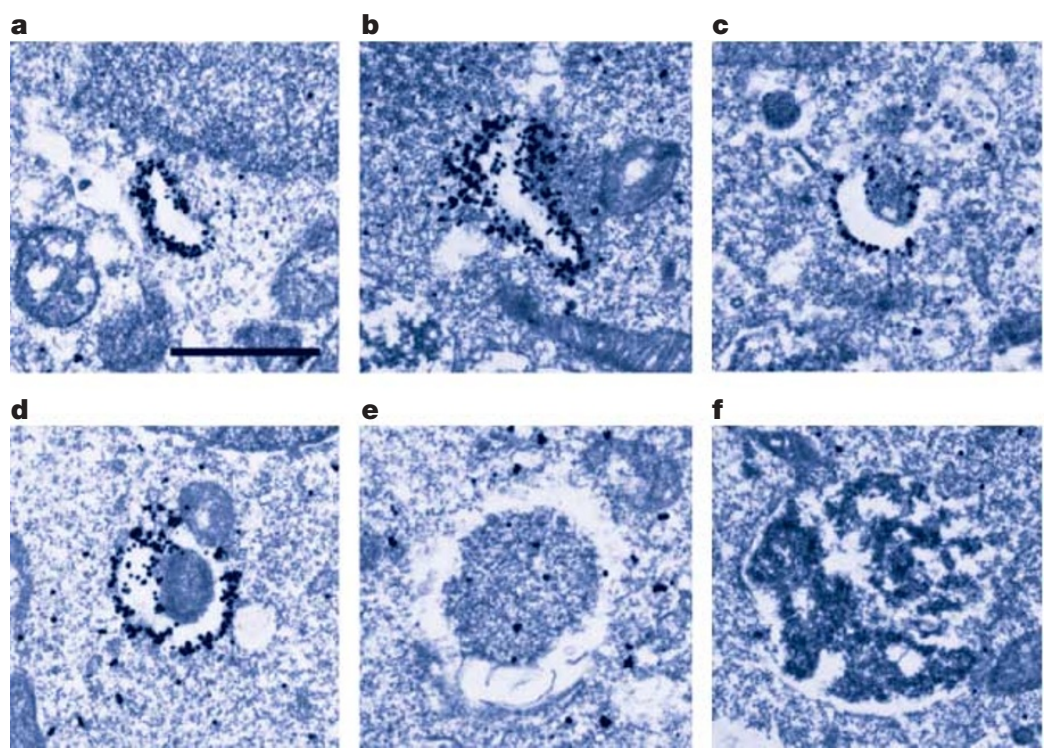

Figure 1 | Immunoelectron microscopy of GFP-Atg5-expressing human cells undergoing autophagy. Atg $5^{-/-}$mouse embryonic stem cells were stably transfected with yeast Atg5 tagged with green fluorescent protein (GFP-Atg5) and cultured in Hanks' solution for $2 \mathrm{~h}$ to induce autophagy. The localization of GFP-Atg5 was examined by silver-enhanced immuno-gold electron microscopy using an anti-GFP antibody. a-d | A series of images showing the presumed progression of membrane extension and cytosolic sequestration during autophagosome formation. e $\mid$ An example of an autophagosome. $\mathbf{f} \mid$ An example of an autolysosome. Scale bar, $1 \mu \mathrm{m}$. Reproduced with permission from REF. 17 () (2001) Rockerfeller University Press.

PEROXISOME

A single-membrane-bound organelle that performs many metabolic functions.

RAPAMYCIN

An immunosuppressive macrolide that inhibits the proliferation of $\mathrm{T}$ and $\mathrm{B}$ cells and was originally isolated from Streptomyces hygroscopicus.

TAMOXIFEN

An antagonist of oestrogen that is used in the treatment of breast cancer.

\section{OKADAIC ACID}

A specific inhibitor of protein phosphatases that acts as a tumour promoter. Okadaic acid is the toxin responsible for diarrhaetic shellfish poisoning.

UBIQUITYLATION

Proteins tagged with ubiquitin can be recognized by the proteasome and degraded.

\section{Autophagic structures}

Studies of cells undergoing autophagy using EM show structures surrounded by two distinct lipid bilayers; these structures are known as autophagosomes (FIG. 1). The inner membranes of these structures surround material that has an electron density equivalent to that of the cytoplasm, whereas the lumenal area between the two delimiting membranes is electron-transparent. Autophagosomes are large - with diameters of 400-900 nm in yeast and 500-1,500 nm in mammalian cells ${ }^{12}$ - and contain cytoplasm and cytoplasmic organelles, such as fractured endoplasmic reticulum (ER), mitochondria and PEROXISOMES. Autophagosomes also contain a mixture of protein markers from the ER, endosomes and lysosomes, as well as bulk-cytosolic contents ${ }^{13-15}$. A list of the markers that are used to identify autophagosomes is provided in TABLE 1.

The presence of markers from a variety of cellular sources makes it difficult to determine the origins of autophagosomal membranes. On the basis of ultrastructural observations and the recognition of autophagosomes by antiserum against proteins of the rough ER, the ER has been suggested as the source of these membranes ${ }^{16}$. An alternative hypothesis is that the fusion of small, lipid-containing vesicles forms a unique C-shaped structure, which is known as the 'sequestration crescent'. This is supported by the observation of small, membranous structures that are labelled by the Atg 5 protein, which could be structural precursors of the mature autophagosome $e^{17}$. The presumed progression of this structure from initiation to the closure of the sequestering membranes into an autophagosome is shown in FIG. 1. The final resolution of these hypotheses might have to await the development of cell-free systems to study autophagosome formation. Although autophagy takes its name from the destruction of cellular constituents, it is clear that several processes constitute the autophagic pathway, including cell signalling, membrane rearrangements and compartmental mixing, in addition to the ultimate degradation of sequestered cytosol.

\section{The autophagic pathway and its mechanisms}

Autophagy can be divided into three stages: initiation, execution and maturation (FIG. 2). The initiation of autophagy can be triggered by a variety of extracellular signals, including nutrient starvation and treatment with hormones. One target of these signals is TOR (target of RAPAMYCIN), a kinase that inhibits the autophagic pathway until this protein is inactivated by dephosphorylation. TOR is a global cell regulator that also controls protein translation and amino-acid synthesis ${ }^{18}$. Rapamycin and nutrient starvation cause the dephosphorylation of TOR, which, in turn, activates the autophagic pathway. A third compound, TAMOXIFEN, is known to induce autophagy, but it is not known whether this is mediated through TOR or a different pathway ${ }^{19}$.

Studies in cancer cell lines have shown that trimeric $\mathrm{G}_{\mathrm{i} 3}$ proteins and class I and II phosphatidylinositol-3-kinases (PI3Ks) function in a step that takes place before autophagic sequestration ${ }^{20,21}$. In fact, high concentrations of amino acids have recently been shown to result in the inactivation of trimeric G proteins, indicating the existence of another mechanism, in addition to the inhibition of the TOR pathway, by which amino-acid depletion might activate autophagy ${ }^{22}$. Many commonly used inhibitors of autophagy, including 3-methyladenine (3-MA), wortmannin and LY294002, target all cellular PI3Ks. However, it has been shown that it is the class III PI3Ks - and the phosphotidylinositol-3-phosphate that they produce - that are essential for starvationinduced autophagic signalling and autophagosome formation $^{21}$. The autophagic sequestration of cytosol was also shown to be inhibited by OKADAIC ACID, indicating a role for protein phosphatase $2 \mathrm{~A}$ in starvationinduced autophagosome formation ${ }^{23}$. In summary, the signals that induce autophagy are mediated by TOR, PI3Ks, protein phosphatases and trimeric G proteins through pathways that are, so far, incompletely understood.

The key stages of autophagosomal execution are mediated by two very interesting covalent-conjugation pathways: the covalent linkage of Atg5 and Atg12, and the covalent lipidation of Atg8 by phosphatidylethanolamine. The enzymes that mediate these conjugations - Atg3, Atg7 and Atg10 - are homologues of enzymes that are involved in protein UBIQUITYLATION $^{24,25}$. Unlike ubiquitylation, however, protein conjugation in autophagy is used to modify pathway components and not to label substrates for degradation. 
Table 1 | Assays used to quantify autophagy and identify autophagic structures

\begin{tabular}{|c|c|}
\hline Assay & Method \\
\hline \multicolumn{2}{|l|}{ Microscopy } \\
\hline EM: ultrastructure & $\begin{array}{l}\text { Direct observation of double- or multi-membrane- } \\
\text { bound structures with lumenal contents }\end{array}$ \\
\hline $\begin{array}{l}\text { EM: volumetric } \\
\text { analysis }\end{array}$ & $\begin{array}{l}\text { Estimation of the volume contained in } \\
\text { autophagosomes compared with the total } \\
\text { cytoplasmic volume }\end{array}$ \\
\hline $\begin{array}{l}\text { EM: morphology } \\
\text { analysis }\end{array}$ & $\begin{array}{l}\text { Direct observation to count relative numbers of } \\
\text { autophagosomes and mature autolysosomes }\end{array}$ \\
\hline MDC staining & $\begin{array}{l}\text { MDC fluorescence is excitable in the ultraviolet } \\
\text { range and is stimulated in a membranous } \\
\text { environment }\end{array}$ \\
\hline LysoTracker & A fluorescent dye that stains acidic compartments \\
\hline DAMP staining & $\begin{array}{l}\text { Incubation of cells with this non-fluorescent } \\
\text { compound stains acidic compartments. } \\
\text { Detection by anti-DNP antibodies can be used in } \\
\text { both fluorescent and electron microscopy. }\end{array}$ \\
\hline
\end{tabular}

Comments

Biochemistry

LDH sequestration Determination of cytosolic LDH activity in purified membrane fractions

\section{Sequestration of $\left[{ }^{3} \mathrm{H}\right]$-sucrose or $\left[{ }^{3} \mathrm{H}\right]$-raffinose \\ Degradation of long-lived proteins \\ Electrodisruption of cells in the presence of a radiolabelled inert sugar allows the quantification of cytosol trapped in membrane fractions \\ Radioactive labelling of proteins followed by incubation with unlabelled amino acids allows measurement of the rate of degradation of long- lived proteins, which increases during autophagy \\ LC3 lipidation LC3I (non-lipidated) and LC3II (lipidated) forms can be separated by SDS-PAGE}

Identification of autophagosomal structures depends on the user's definition of double- or multi-membrane-bound vesicles and careful control of fixation conditions. However, because double-membrane-bound structures with cytosolic contents are uncommon, observation of these can be highly suggestive of autophagy.

Requires careful morphometric analysis of many EM images

Autophagosomes and autolysosomes can be distinguished by the higher electron density of the latter. Evidence obtained can be greatly strengthened by combining this assay with immunostaining.

Fixation of cells after MDC staining is essential for its use as a specific stain for autophagosomes, otherwise staining is observed for any polarized membrane. Positive controls for bona fide autophagy in the cell type of interest are crucial. Not specific for autophagosomes and will identify any acidic compartment Not specific for autophagosomes

Dependent on integrity of autophagosomal membranes and innate LDH activity of cells used. Concurrent positive and negative controls are necessary. Degradation of LDH in autolysosomes can lead to underestimation of autophagic sequestration.

Integrity of internal membranes after electrodisruption needs to be confirmed in each cell type. Concurrent positive and negative controls are necessary.

Degradation of long-lived proteins requires completion of the autophagic pathway, as it is associated only with autolysosome formation. Any inhibition of the pathway before complete maturation should not markedly increase the rate of degradation. However, this remains the most definitive functional marker of the uninterrupted autophagic pathway.

Observation of the lipidated LC3II form is likely to be a definitive marker of activation of the autophagic pathway, as it has not yet been seen in its absence

\section{Detection of autophagosomal markers}

\begin{tabular}{|ll} 
Atg5 detection & $\begin{array}{l}\text { Detection of fluorescent GFP-Atg5 fusion } \\
\text { protein or immunodetection of endogenous protein }\end{array}$ \\
\hline LC3 detection & $\begin{array}{l}\text { Detection of fluorescent GFP-LC3 fusion protein } \\
\text { or immunodetection of endogenous protein }\end{array}$
\end{tabular}

Atg7 detection Immunodetection of endogenous protein

Atg5 is only seen on autophagosomes during formation and is not present after completion. Atg5 can be seen most often as an Atg5-Atg12 complex.

LC3 localization within cells can be either diffuse or punctate in the absence of autophagosome formation, therefore co-staining with other markers enhances the certainty of identifying autophagosomes by punctate LC3 staining Although Atg7 is thought to be present only transiently during autophagosome formation, it has been used to identify potentially autophagic structures, which are perhaps arrested at an early stage

\section{Known organelle markers}

Detection of BiP, Detection of fluorescent GFP-fusion proteins or PDI, Sec61b, LAMP1/2 and immunodetection of endogenous protein

Not specific for autophagosomes, but combined with other markers can show that a pooled compartment has been formed that is consistent with an autophagic structure

cathepsins

Acid-phosphatase Activity can be used to precipitate heavy metals detection on the surface of samples prepared for EM analysis

Not specific for autophagosomes, but combined with other markers can show that a pooled compartment has been formed that is consistent with an autophagic structure

DAMP, N-(3-[2,4-dinitrophenyl]-amino) propyl-I-N (3-aminopropyl-methylamine) dihydrochloride; DNP, dinitrophenol; EM, electron microscopy; GFP, green fluorescent protein; LAMP, lysosome-associated membrane protein; LC3, microtubule-associated-protein light-chain 3; LDH, lactate dehydrogenase; MDC, monodansyl cadaverine; PDI, protein disulphide isomerase; SDS-PAGE, sodium dodecyl sulphate polyacrylamide-gel electrophoresis.

The covalent linkage of Atg5 and Atg12 is accomplished in several steps: the carboxy-terminal glycine of the 187-amino-acid Atg12 protein is activated by transient covalent linkage first to Atg7 and then to Atg10, before becoming covalently attached to Lys130 of Atg5 (REFS 26-28). Mutant forms of the Atg5 protein that lack the lysine residue that is necessary for conjugation do not form Atg5-Atg12-Atg16 complexes or autophagosomes, but still associate with membranes. This indicates that Atg5 itself contains a membrane-targeting domain, and is perhaps responsible for the targeting of the entire complex ${ }^{17}$. As shown in FIGS 1 and 2, the 


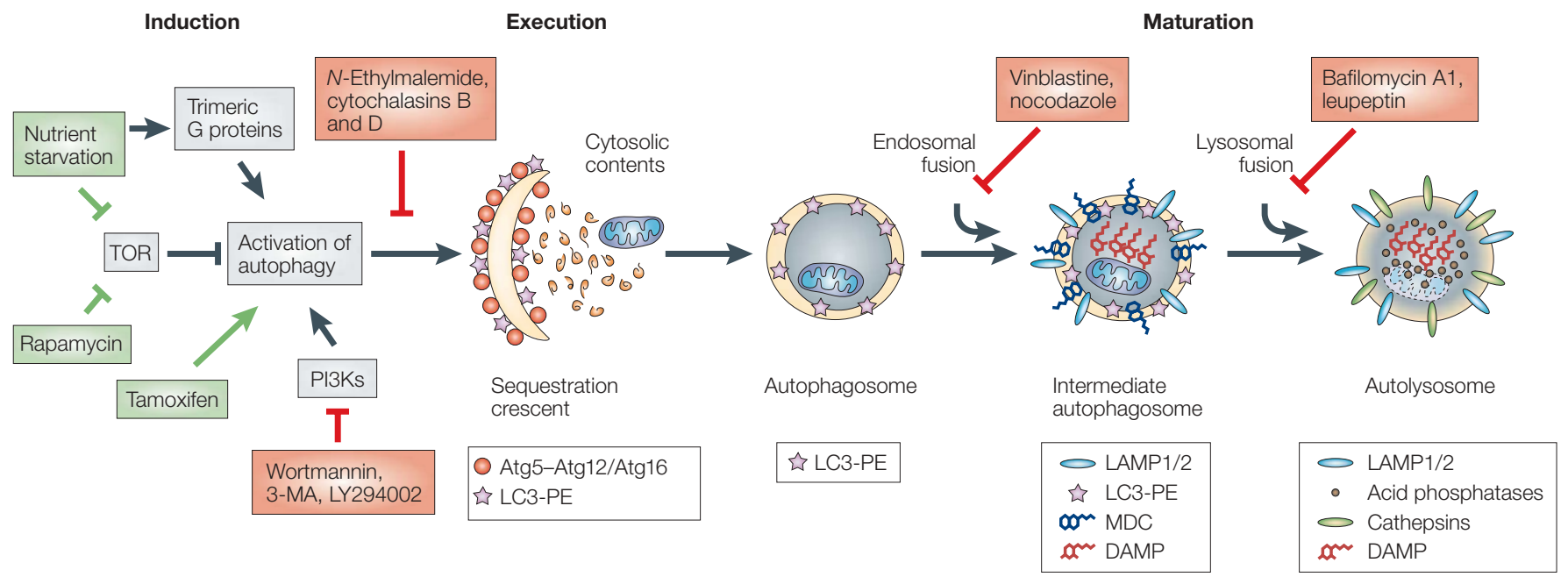

Figure 2 | The autophagic pathway. The known steps of induction, execution and maturation of autophagosomes and autolysosomes. Green lines and arrows indicate activation or inhibition events, respectively, that induce autophagy; red lines indicate events that inhibit autophagy. The markers that are present at each morphological step are indicated in the key, as are several known inhibitors and the steps at which they are thought to act (red boxes). Caution must be used in interpreting the results obtained using all of these inhibitors, due to their pleiotropic effects. 3-MA, 3-methyladenine; DAMP, N-(3-[2,4-dinitrophenyl]-amino) propyl-IN-(3-aminopropyl-methylamine) dihydrochloride); LAMP, Iysosome-associated membrane protein; LC3, microtubule-associated-protein light-chain 3; MDC, monodansylcadaverine; PE, phosphatidylethanolamine; PI3K, phosphatidylinositol-3-kinase; TOR, target of rapamycin.

CATHEPSIN

A lysosomal protease that functions optimally within an acidic $\mathrm{pH}$ range.
Atg5-Atg12-Atg16 complex is present only on the sequestration crescent, a double-membrane-bound structure that engulfs cytosolic constituents to become the apparently closed, double-membrane-bound autophagosome.

The second conjugation pathway results in the covalent addition of the lipid phosphatidylethanolamine to the newly generated carboxyl terminus of microtubule-associated-protein light-chain 3 (LC3), the human homologue of $S$. cerevisiae Atg8. The carboxy-terminal amino acids of LC3 are cleaved by the cysteine protease Atg4 to leave a conserved glycine residue. Cleaved LC3 is then transiently linked to the Atg7 protein, then to Atg3, and finally to phosphatidylethanolamine ${ }^{29}$. Lipidation of LC3 is necessary and sufficient for membrane association and, as shown in FIG. 2, modified LC3 remains associated with autophagosomes until destruction at the autolysosomal stage.

After formation, autophagosomes fuse with endosomal vesicles and acquire lysosome-associated membrane protein 1 (LAMP1) and LAMP2, and gain the ability to accumulate DAMP ( $N$-(3-[2,4-dinitrophenyl]amino) propyl-1-N (3-aminopropyl-methylamine) dihydrochloride), thus becoming intermediate autophagosomes $^{30}$ (FIG. 2). These structures fuse with lysosomes and acquire CATHEPSINS and acid phosphatases to become mature autolysosomes (FIG. 2). Vesicle fusion is often mediated by small GTPases, such as the RAB proteins $^{31}$. Recently, Rab24, an orphan small GTPase, was shown to associate specifically with autophagosomes and, although its roles in autophagosome trafficking, fusion and maturation are not yet known, this might provide an important clue to the late events of autophagosome formation, as well as providing an additional marker for autophagic structures ${ }^{32}$.

\section{Assays for the autophagic pathway}

There are many methods for identifying and quantifying autophagosome formation and function (TABLE 1). The analysis of cells by EM as they undergo autophagy is a classic and important method. Autophagy can be quantified from electron micrographs, and this often involves estimating the volume that is contained within the autophagosomal structures compared with that in the remainder of the cytoplasm. Furthermore, autophagosomes can be divided into two classes on the basis of their morphology, as shown by EM: immature (or early) autophagosomes (FIG. 1d,e) contain two or more bilayers surrounding cytoplasmic material, whereas mature autolysosomes (FIG. 1f) have a more homogeneous density and lose the distinctive inner membrane of early autophagosomes.

Unfortunately, very few proteins are specifically retained in autophagosomes. Whereas Atg5 only labels the earlier autophagosomal structures (FIG. 1), both S. cerevisiae Atg8 and its human homologue LC3 are retained in autophagosomal membranes until maturation is complete ${ }^{29}$. The use of these markers in immunoelectron and fluorescence microscopy greatly facilitates the identification of autophagosomal structures ${ }^{33}$.

Some methods of autophagosome identification use compounds that accumulate in and label the various cellular compartments and organelles that participate in autophagosome formation. One such compound is LysoTracker (Molecular Probes, USA), which normally stains lysosomes ${ }^{34}$. DAMP is a non-fluorescent molecule that, similarly to LysoTracker, accumulates in acidic compartments ${ }^{30}$. Individually, these compounds do not uniquely stain autophagosomes; however, when used in conjunction with the detection of proteins in the autophagic pathway, they can help researchers to distinguish autophagosomes from other structures in the cell. 
Monodansylcadaverine (MDC), a fluorescent compound, has also been shown to stain autophagosomes ${ }^{35}$. MDC can be incorporated into living cells, where it stains polarized membranes and becomes fluorescent on excitation with ultraviolet light. Specificity for autophagosomes is achieved after detergent-free fixation, presumably after polarity is lost across single membranes but is maintained by the double membranes of autophagosomes. However, there is confusion in the literature as to the importance of fixation in the use of MDC. In the absence of fixation, this stain is probably no more a specific autophagosome stain than are LysoTracker or DAMP.

The quantification of autophagosome formation has relied primarily on biochemical assays for cytosolic sequestration. Sequestration assays for lactate dehydrogenase $(\mathrm{LDH})$ and $\left[{ }^{3} \mathrm{H}\right]$-labelled inert sugars can be used to measure the amount of sequestered cytosolic material that is trapped within autophagic structures after separation of membranes from the cytosol ${ }^{14,36}$. The quantification of sequestered $\mathrm{LDH}$ is an excellent assay, but it is predicted to underestimate the amount of cytoplasm trapped by autophagosome formation because any $\mathrm{LDH}$ that has progressed to autolysosomes will be degraded.

To monitor the end-point of the autophagic pathway - the degradation of engulfed cytosolic constituents - the destruction of long-lived proteins can be measured. Cells are usually metabolically labelled with $\left[{ }^{3} \mathrm{H}\right]$-leucine or $\left[{ }^{14} \mathrm{C}\right]$-valine and are then incubated in the absence of labelled amino acids for $48 \mathrm{~h}$ to allow short-lived proteins to be degraded. The rate of loss of the remaining labelled protein is then determined; autophagy is associated with an increase in this rate ${ }^{36}$. The analysis of changes in the degradation rate of longlived proteins has long been considered to be the best method to diagnose autophagy. However, as many microorganisms themselves encode proteases, potentially causing the overestimation of autophagic processes, and can inhibit autophagosomal maturation, potentially causing the underestimation of autophagosome formation, this method should used in combination with other assays.

The discovery of the ATG genes and other genes that are required for autophagy in yeast and mammalian cells provides an outstanding method to diagnose whether a process of interest, such as a bacterial or viral infection, requires the wild-type function of these genes. Investigators are now beginning to use the genetics of mice, plants, nematodes and Drosophila, and RNA interference in human cells, to test the effect of eliminating or reducing the expression of these genes on processes of interest, such as development, transformation and microbial infection. The attribution of any effect of reduced gene function to the effect of that gene on autophagy clearly relies on the assumption that the only function of that gene is in autophagy. Nevertheless, the newly identified homologues of the yeast ATG genes provide powerful new tools to dissect the mechanism of autophagy and its role in many cellular processes of interest.

\section{Bacterial susceptibility to autophagy}

A relationship between autophagy and bacterial infection has been postulated in the infection of the plant Astragalus sinicus by Mesorhizobium huakuii ${ }^{37}$. The bacteria differentiate within membrane-bound compartments, showing an altered morphology, until they can fix nitrogen and enter into a symbiotic relationship with the plant. Evidence of bacterial degradation has been seen in conditions of nutrient starvation in infected plant nodules. This has led to the hypothesis that autophagy, which is potentially induced by nutrient depletion in the soil, causes the plant to destroy infecting bacteria before their differentiation into a nitrogenfixing form, as there would be no advantage to the plant to support the symbiont under these conditions.

One of the first examples of bacteria being found within potentially autophagic structures was the observation of Rickettsiae species in double-membranebound vesicles that contained acid phosphatases ${ }^{38}$. Subsequently, correlations between the presence of double-membrane-bound structures and bacterial destruction were shown. The growth of Rickettsia conorii was found to be sensitive to interferon (IFN) or tumour-necrosis factor- $\alpha$ (TNF- $\alpha$ ) treatment of host mice or mouse-derived cells, and these cytokine treatments correlated with increases in cellular nitric oxide (NO) production ${ }^{39-41}$. In the presence of these cytokines, EM imaging of infected mouse endothelial cells clearly showed bacteria surrounded by double membranes, and in some cases the bacteria seemed to be damaged, perhaps due to degradation ${ }^{42}$. It was also shown that providing an intracellular NO donor could partially mimic the anti-rickettsial effects of cytokines and that a competitive inhibitor of NO synthesis could abrogate these effects ${ }^{42}$. NO is known to play an important antimicrobial role in innate immunity, which suggests the possibility that NO production directly activates autophagy as a mechanism for killing invading bacteria. Alternatively, it is possible that bacteria are killed by reactive oxygen species and are subsequently taken up by autophagosomes for degradation. It would be interesting to determine whether treatment with NO donors has a direct effect on autophagy and to look for potential correlations between NO production, autophagy and bacterial survival.

A recent report indicates that Listeria monocytogenes can be targeted by autophagosomes ${ }^{43}$. L. monocytogenes normally enters host cells by phagocytosis, after which the bacteria escape from the phagosome and multiply within the host-cell cytoplasm. Mutant $\Delta a c t A$ bacteria, which are incapable of polymerizing actin, can escape from the entry phagosomes but are defective in the ability to spread intracellularly and intercellularly and become engulfed by double-membrane-bound vesicles. Treatment with wortmannin, which is known to inhibit autophagy, reduces bacterial entry into these putative autophagosomes, whereas serum starvation of infected cells was found to increase bacterial uptake into the membranous vacuoles. Furthermore, bacteria-filled autophagosomes have been identified by EM imaging and by the colocalization of LAMP1 and bacterial antigens ${ }^{43}$. 
Infection by the intracellular bacterium Salmonella typhimurium is known to kill human macrophages by two different routes: a rapid, apoptotic route that is mediated by the binding of the secreted bacterial protein SipB to host caspase 1 (REF. 44) and a slower, caspase-1-independent mechanism. The ultrastructure of caspase $1^{-/-}$macrophages that are infected with wild-type S. typhimurium, but not those that are infected with type-III-secretion-defective SipD mutant bacteria, shows characteristics of autophagy, such as post-fixation staining with MDC and increased numbers of multilamellar vesicles ${ }^{45}$. However, as for all the examples in this section, it is not yet known if the apparently autophagic structures that are induced during S. typhimurium infection of macrophages have any role in restricting bacterial growth.

\section{Bacterial subversion of the autophagic pathway} In contrast to those described above, several types of bacteria can subvert the autophagic pathway and replicate inside compartments that are decorated with characteristic components of autophagosomes. For example, Porphyromonas gingivalis, which can infect human coronary-artery endothelial cells, has been shown to localize to membranous compartments that are suspected to be autophagosomes because of the presence of ER markers early in the bacterial replication cycle and the later addition of lysosomal markers ${ }^{46,47}$. When wortmannin was added to the host cells, which presumably prevents the initial formation of autophagosome-like structures, a qualitative change in the bacterial vacuole was seen: the vesicles resembled lysosomes rather than autophagosomes and acquired cathepsin L earlier in their formation and before ER markers were acquired. In terms of function, the survival of intracellular P. gingivalis was greatly reduced in the presence of either 3-MA or wortmannin, which indicates that the lysosomal fate that was apparently caused by these treatments was detrimental to the bacteria.
Most examples of potential autophagic subversion by bacteria require the function of bacterial type IV secretion pathways, which are homologous to conjugal plasmid-transfer systems and bring about the uptake of bacterial proteins into infected cells. For example, after endosomal uptake into mammalian cells, Brucella abortus localizes to structures that resemble autophagosomes as they have double membranes and display markers from the ER and late endosomes ${ }^{48,49}$. Consistent with a positive role for autophagy or autophagic components in bacterial replication, both 3-MA and wortmannin were found to reduce Brucella growth, whereas host-cell starvation slightly increased bacterial yield. The Brucella virB operon encodes members of a type IV secretion pathway, $\operatorname{vir} B$ mutants are defective in normal intracellular transport and growth ${ }^{50,51}$, and the compartments they localize to acquire cathepsin D almost immediately. For both P. gingivalis and B. abortus, it has been proposed that, on entry into cells, the bacteria immediately enter newly induced autophagosomes. Failure to enter autophagosomes, due to wortmannin treatment or $\operatorname{vir} B$ mutations, results in the bacteria being taken up by lysosomes and degraded, as shown in FIG. $3 b^{47,48,52}$.

One well-studied example of a bacterium that relies on a type IV secretion pathway to avoid a lysosomal fate is Legionella pneumophila, which is a Gram-negative pathogen that can replicate within human macrophages. In experiments that have implicated the autophagic machinery in the formation of the membranous vacuoles inside which Legionella replicates, these compartments have been shown by EM to be surrounded by double membranes and to contain markers such as the ER-resident protein BiP, the lysosomal/endosomal marker LAMP1 and, in a smaller percentage of vesicles, the lysosomal protein cathepsin $\mathrm{D}^{53-56}$. Genes for which mutations cause defects in organelle trafficking or intracellular multiplication — known as the dot or icm genes - are
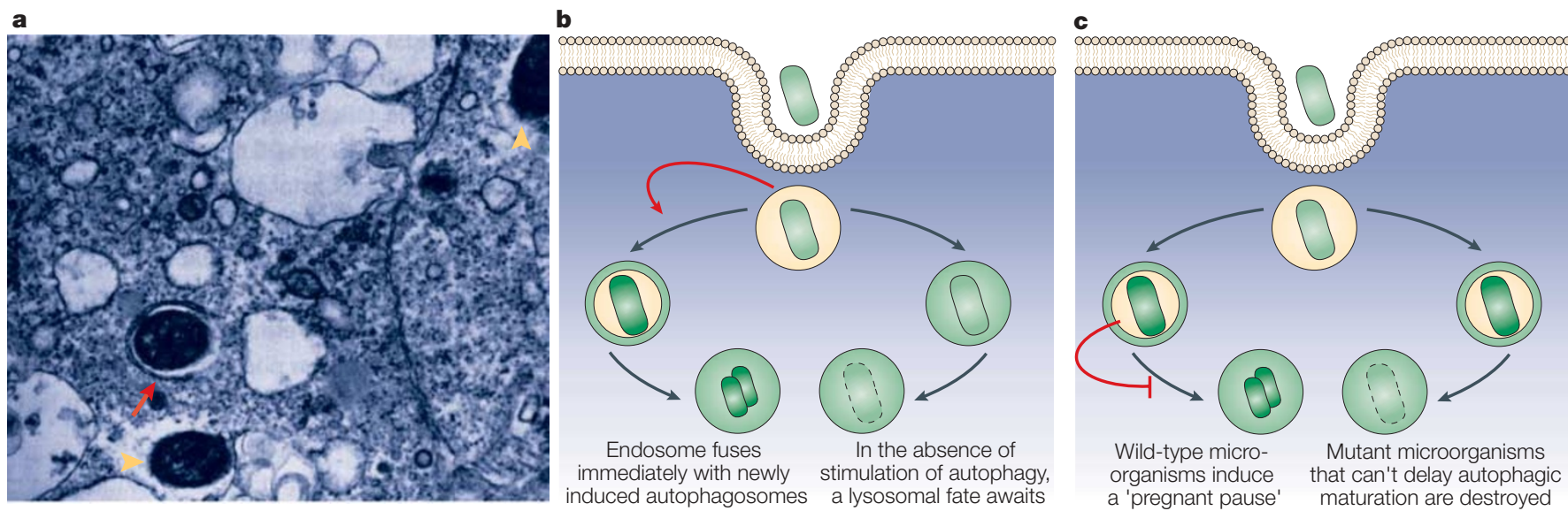

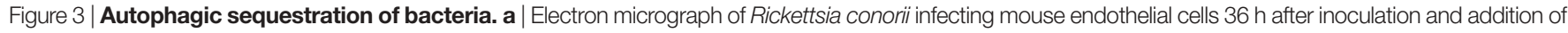
cytokines. The arrow indicates a rickettsial cell that is contained within a double-membrane-bound compartment. Arrowheads indicate intact $R$. conorii in the cytosol. b | A situation in which bacterial infection stimulates autophagosome function (red arrow) and the bacteria avoid a phagosomal fate, as has been proposed for Porphyromonas and Brucella infection. c | A situation in which bacterial infection delays autophagosome formation (red blunt-ended arrow), as has been proposed for Legionella and Rickettsia infection. a reproduced with permission from REF. 42 @ (1997) Nature Publishing Group. 
required for Legionella replication in human macrophages, but not in bacterial growth medium. Legionella bacteria in which the dot/icm genes are mutated were shown to be mistargeted early in infection and did not localize to double-membrane-bound vesicles, but to vesicles with late endosomal or lysosomal characteristics ${ }^{55,57-59}$. Further work showed that the dot/icm genes encode the proteins of a type IV secretion system ${ }^{60-62}$. In the 'pregnant pause' model ${ }^{11}$, Legionella and other vacuole-associated pathogens enter the cell and localize to autophagosomes. Then, through the action of bacterial proteins that require the type IV secretion apparatus to enter the host cytoplasm, the maturation of these autophagosome-like structures into autolysosomes is delayed. It has been proposed that this delay gives the microorganisms time to develop into replicative forms that can withstand the environment of the autolysosome (FIG. 3c).

However, the autophagosomal origin of the Legionella replication compartments has been disputed. Some ultrastructural EM analyses have shown structures that seem to be rough ER surrounding the bacteria ${ }^{63}$. In addition, formation of the compartment was shown to be sensitive to dominant-negative alleles of SAR1 and $A R F 1$, genes that encode small GTP-binding proteins that are classically involved in traffic between the ER and the Golgi apparatus ${ }^{64}$. In D. discoideum, which is a natural host for Legionella, loss-of-function alleles of the atg1, atg5, atg6, atg7 and atg8 genes showed the expected defects in autophagy, but there was no effect either on the growth of L. pneumophila or on the morphology of its replication compartments ${ }^{65}$. It is, of course, possible that the bacterium uses different replication strategies in these different hosts. Now that analogous genetic approaches can be used in mammalian cells, it will be possible to test whether loss-of-function alleles of genes that are required for autophagy affect the function, composition or ultrastructure of the Legionella replication compartments in human macrophages.

A bacterium that is closely related to Legionella, Coxiella burnetii, is the causative agent of Q fever. Like Legionella, C. burnetii has been shown to replicate within acidic vesicles ${ }^{66,67}$. These Coxiella replication compartments also show some autophagic characteristics, such as labelling with the autophagy-specific marker LC3, as well as lysosomal and late endosomal markers ${ }^{34,66,68-71}$. Expression of a dominant-negative form of Rab7 altered the size and number of these Coxiella-containing compartments, consistent with a role for lysosomal fusion in their maturation ${ }^{34}$. If the autophagic pathway is involved in the formation of these compartments, lysosomal fusion ability could affect either the autophagic induction or pregnant pause models for the bacterial use of autophagic constituents, and these ideas

\begin{tabular}{|c|c|c|}
\hline Inhibitor & Mechanism & References \\
\hline Herpesvirus US11 & RNA-binding protein; prevents PKR activation by dsRNA & 107 \\
\hline Vaccinia E3L & RNA-binding protein; prevents PKR activation by dsRNA & 108 \\
\hline Avian reovirus sA & RNA-binding protein; prevents PKR activation by dsRNA & 109 \\
\hline Reovirus s3 & RNA-binding protein; prevents PKR activation by dsRNA & 110 \\
\hline Influenza virus NS1 & RNA-binding protein; prevents PKR activation by dsRNA & 111 \\
\hline Epstein-Barr virus SM & RNA-binding protein; prevents PKR activation by dsRNA & 112 \\
\hline Adenovirus VA1 RNAs & $\begin{array}{l}\text { Bind to PKR without activating its kinase activity to inhibit PKR activation } \\
\text { by dsRNA }\end{array}$ & 113 \\
\hline $\begin{array}{l}\text { Epstein-Barr EBER } \\
\text { RNAs }\end{array}$ & $\begin{array}{l}\text { Bind to PKR without activating its kinase activity to inhibit PKR activation } \\
\text { by dsRNA }\end{array}$ & 114 \\
\hline HIV TAR RNA & $\begin{array}{l}\text { Binds to PKR without activating its kinase activity to inhibit PKR activation } \\
\text { by dsRNA }\end{array}$ & 115,116 \\
\hline Influenza virus & $\begin{array}{l}\text { Induces expression of cellular p58IPK protein, which binds PKR and prevents } \\
\text { its activation by dsRNA }\end{array}$ & 117,118 \\
\hline Poliovirus & Decreases stability of PKR by an unknown mechanism & 119 \\
\hline Baculovirus PK2 & Forms complex with PKR, inhibiting its kinase activity & 120 \\
\hline HCV NS5A & Forms complex with PKR, inhibiting its kinase activity & 121 \\
\hline Herpesvirus US11 & Forms complex with PKR, inhibiting its kinase activity & 107 \\
\hline HIV TAT & Forms complex with PKR, inhibiting its kinase activity & 122 \\
\hline Vaccinia K3L & elF2 $\alpha$ homologue; prevents elF2 $\alpha$ phosphorylation and binds directly to PKR & 123 \\
\hline Myxoma virus M156R & elF2 $\alpha$ homologue; prevents elF2 $\alpha$ phosphorylation and binds directly to PKR & 124 \\
\hline $\begin{array}{l}\text { Kaposi's-sarcoma- } \\
\text { associated herpesvirus } \\
\text { LANA2 }\end{array}$ & Prevents elF2 $\alpha$ phosphorylation by activated PKR & 125 \\
\hline Herpesvirus ICP34.5 & $\begin{array}{l}\text { Complexes with protein phosphatase } 1 \text { to dephosphorylate elF2 } \alpha \text {, reversing } \\
\text { the effect of PKR }\end{array}$ & 126 \\
\hline SV40 infection & $\begin{array}{l}\text { Allows normal translation in presence of phosphorylated elF2 } \alpha \text { by an unknown } \\
\text { mechanism }\end{array}$ & 127 \\
\hline
\end{tabular}

dsRNA, double-stranded RNA; elF2 $\alpha$, eukaryotic translation initiation factor $2 \alpha$; $\mathrm{HCV}$, hepatitis $\mathrm{C}$ virus; SV40, simian virus 40. 


\section{Box 1 | Signalling pathways involving PKR}

What is perhaps the most convincing evidence that the activation of PKR is strongly antiviral comes from the fantastic lengths that viruses take to avoid PKR activation and its consequences (TABLE 2). PKR was originally discovered because of its antiviral role during infection ${ }^{103}$. Double-stranded RNA (dsRNA) is often present during viral infections, either as a byproduct of the replication of RNA viruses or as a product of overlapping transcription from the compact genomes of DNA viruses. dsRNA is a known allosteric effector of PKR and causes a conformational change in PKR, which is followed by its dimerization and activation of its kinase activity. On activation, PKR phosphorylates several substrates, including other PKR monomers, the regulatory subunit of protein phosphatase $2 \mathrm{~A}(\mathrm{PP} 2 \mathrm{~A})$, and the eukaryotic translation initation factor eIF2 $\alpha$. Phosphorylation is known to increase the activity of the PP2A complex, which has many targets. Phosphorylation of eIF $2 \alpha$ prevents the recycling of the eIF2-GDP complex, which drastically inhibits most translational initiation - both host and viral - which requires the initiator transfer RNA, tRNA $^{\text {met }}$. Some messenger RNAs, however, are selectively translated under conditions of eIF $2 \alpha$ phosphorylation. These include those that require the use of an alternative AUG codon. Reducing the frequency of productive initiation can allow scanning through upstream AUGs ${ }^{104,105}$. Therefore, PKR activation by dsRNA, which is usually described as inhibiting translation, is likely to have more subtle effects on translation than simple inhibition

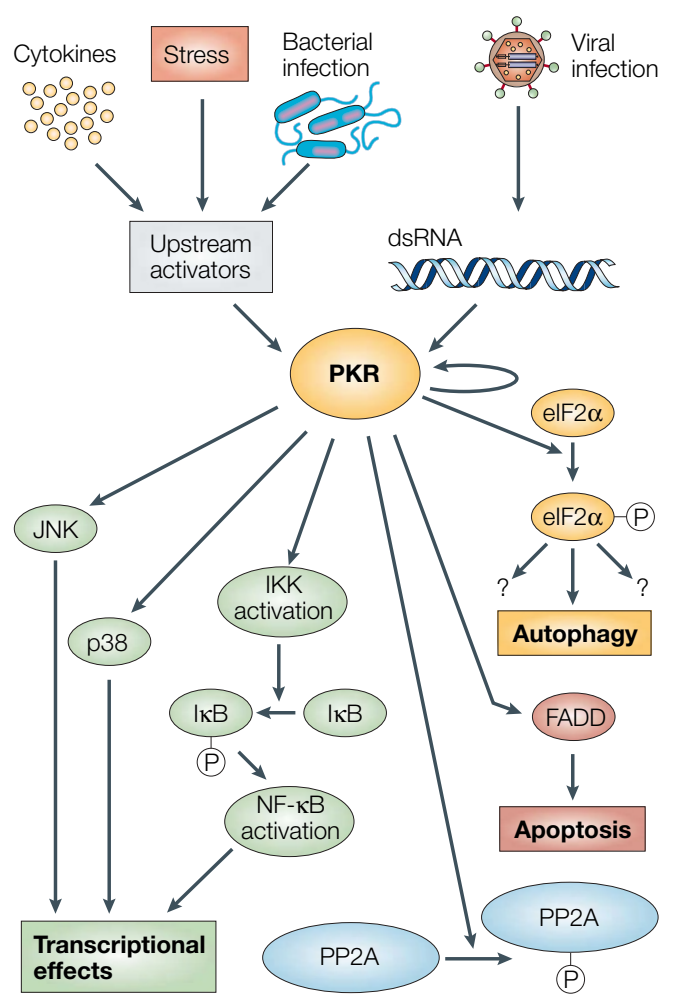
and might actually activate the translation of some mRNAs, especially those with upstream open reading frames.

PKR activation also activates nuclear factor- $\kappa \mathrm{B}(\mathrm{NF}-\kappa \mathrm{B})^{77}$ - a known participant in host antiviral responses — but this occurs through a mechanism that is not thought to require the phosphorylation of eIF2 $\alpha$ or PP2A. Other genes and gene products whose expression is affected by PKR stimulation are shown in the figure. Most of the signal transduction pathways in which PKR is activated do not use the dsRNA activation mechanism, but instead use various upstream effectors, some of which are themselves kinases and can phosphorylate PKR directly.

The mechanisms of action of viral factors that are known to avoid inhibition by PKR (TABLE 2) include RNAs that bind to PKR without activating it, proteins that titrate dsRNA, and eIF2 $\alpha$ decoys that serve as targets for activated PKR and so protect the real translational machinery. Another viral PKR inhibitor, the ICP34.5 gene product that is encoded by herpes simplex virus 1 (HSV1), binds to protein phosphatase 1a, causing it to dephosphorylate eIF2 $\alpha$ and so reverse the effects of phosphorylation of eIF2 $\alpha$ by PKR ${ }^{106}$. Presumably, the expression of ICP34.5 — or any other viral product that neutralizes the effect of eIF2 $\alpha$ phosphorylation by PKR - would also reverse PKR phosphorylation by any of the three other cellular eIF2 $\alpha$ kinases in mammalian cells. These are GCN2, which is activated during amino-acid starvation; pancreatic ER kinase (PERK), which is activated during endoplasmic reticulum stress; and haem-regulated eIF2 $\alpha$ kinase (HRI), which is activated during haem depletion ${ }^{77}$. FADD, FAS-associated death domain; IKB, inhibitor of NF- $\kappa B$; IKK, IKB kinase; JNK, c-JUN amino-terminal kinase.

are clearly not mutually exclusive. The isolation of effector molecules that induce autophagosome formation, delay autophagosome maturation, or both, would strengthen the case for a role for autophagy in the formation of replication vacuoles and would allow the autophagy induction and pregnant pause models to be tested further. It may be found that there are common mechanisms by which bacteria subvert cellular autophagy. Consistent with this view, the dot/icm homologues that are found in Coxiella were shown to rescue the growth defects of Legionella bacteria with dot/icm mutations ${ }^{72}$. Whether the molecules that are transported by these interchangeable type IV secretion machines have similar functions, however, remains to be tested.
Are there likely candidates for type-IV-secretiondependent factors that delay autophagosome maturation? The leading candidates are factors that are expressed in both Legionella and Rickettsia and that display homology to the eukaryotic SEC7 guaninenucleotide-exchange factor, which is known to be involved in membrane fusion and transport ${ }^{60}$. The Legionella SEC7 homologue, RalF, has been shown to be secreted in a type-IV-dependent manner, and recruits the cellular ADP ribosylation factor ARF1 to the membrane of the Legionella phagosome. It is possible, therefore, that RalF might play a role in altering the trafficking of that vacuole ${ }^{62}$. Although mutations in ralF did not affect the yield of intracellular bacteria ${ }^{62}$, it 
a

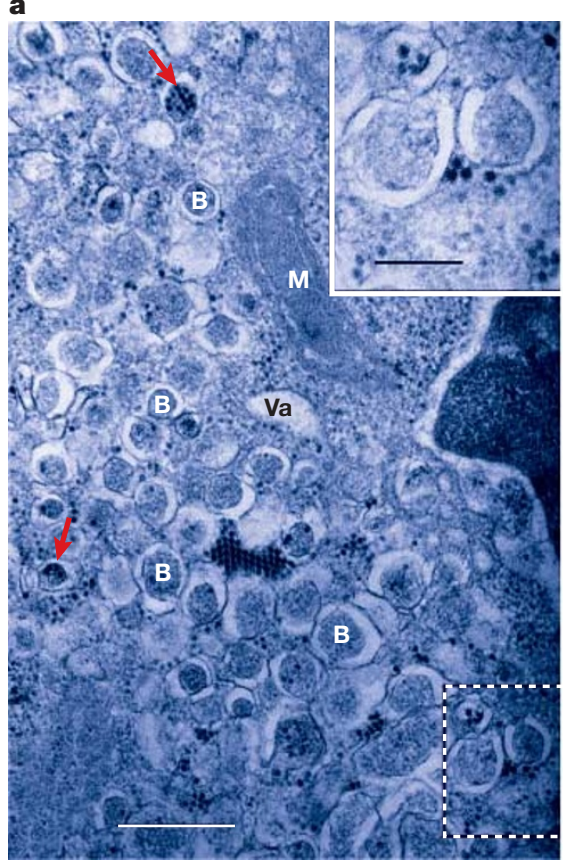

b

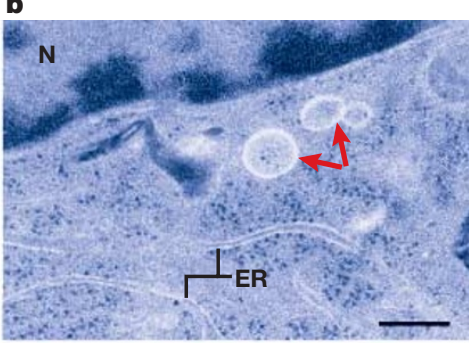

c

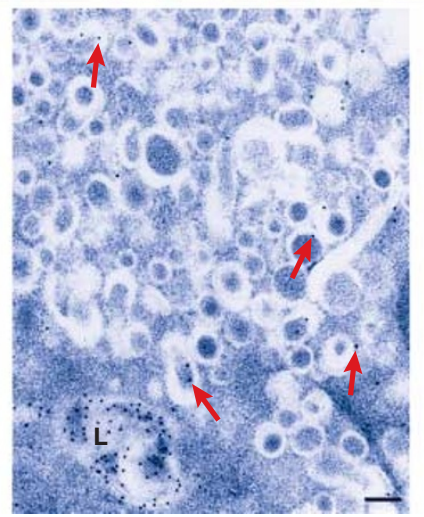

Figure 4 | Formation of double-membrane-bound vesicles during poliovirus infection. | a | Electron micrograph of a chemically fixed, poliovirus-infected HeLa cell $7 \mathrm{~h}$ post-infection. ' $\mathrm{B}$ ' indicates the apparently cytosolic lumens of double-membrane-bound vesicular bodies. 'Va' indicates a vacuole that does not seem to be multilamellar. ' $M$ ' indicates a mitochondrion. Poliovirus particles, either single or in groups, can be seen in the cytoplasm and, occasionally, within the lumen of the double-membrane-bound vesicles (arrows). The inset shows the region outlined by dashed white lines in the main image at a higher magnification. Scale bar in main image, $0.6 \mu \mathrm{m}$; scale bar in inset, $0.25 \mu \mathrm{m}$. b | Electron micrograph of poliovirus-infected HeLa cells $2.5 \mathrm{~h}$ post-infection preserved by high-pressure cryopreservation and freeze substitution. Arrows indicate double-membrane-bound structures with apparently cytosolic lumens that are similar to those seen at later times after infection. Membranes that have distributions and morphologies that are characteristic of the endoplasmic reticulum are indicated (ER). ' $N$ ' indicates the nucleus. Scale bar, $0.2 \mu \mathrm{m}$. c | Immunolocalization of the late endosomal/lysosomal protein LAMP1 in poliovirus-infected HeLa cells $4.5 \mathrm{~h}$ post-infection. Arrows indicate selected gold particles coupled to a secondary antibody. 'L' indicates a lysosome. Scale bar, $0.2 \mu \mathrm{m}$. a reproduced with permission from REF. 79 ( ) (1965) Elsevier Science; b and c reproduced with permission from REF. 85 ( ) (1996) ASM.

is possible that its function in the intracellular growth of Legionella, if any, is redundant in human macrophages.

With regard to possible inducers of autophagy that are secreted by bacteria, one candidate is the Helicobacter pylori cytotoxin VacA, which has multiple effects, including induction of apoptosis, cytochrome $c$ release and inhibition of T-cell activation, depending on the cell type ${ }^{73}$. Among its many effects, VacA has been shown to induce the proliferation of acidic vacuoles that bear late endosomal and lysosomal markers and might, on further investigation, show other hallmarks of autophagosomes ${ }^{73-75}$.

\section{Autophagy and viruses: avoidance and surrender}

A direct role for autophagy in the clearance of herpesvirus from infected cells has been indicated by studies of the course of viral infection in cells that differ in their expression of the double-stranded-RNA-activated protein kinase PKR, a crucial component of the cellular antiviral response (BOX 1). One of the functions of activated PKR is to phosphorylate the eukaryotic translation-initiation

factor eIF $2 \alpha$ and thereby inhibit and deregulate cellular translation. Herpes simplex virus 1 encodes a protein, ICP34.5, that antagonizes this function by redirecting a cellular phosphatase to dephosphorylate eIF $2 \alpha$. The reduction in herpesvirus growth that is caused by the deletion of the gene encoding ICP34.5 was shown to be completely reversed in mice that lack $\mathrm{PKR}^{76}$. Therefore, the sole purpose of the herpesvirus ICP34.5 gene is likely to be to counteract the effects of PKR activation.

What are the antiviral effects of PKR? PKR activation is known to alter cellular translation, induce apoptosis and activate nuclear factor- $\mathrm{KB}(\mathrm{NF}-\kappa \mathrm{B})$, as well as having other, less well-characterized effects (BOX 1$)^{77}$. As shown by Tallozcy et al. ${ }^{78}$, one of the downstream consequences of PKR activation is the activation of autophagy. The infection of wild-type mouse embryonic fibroblasts (MEFs) with wild-type herpesvirus did not cause a significant increase in the amount of degradation of long-lived proteins or an increase in the total volume of autophagic vacuoles ${ }^{78}$. However, similar infections with herpesviruses in which the ICP34.5 gene has been deleted showed an increase in both of these indicators of autophagy, whereas no increased autophagy was seen when either mutant or wild-type herpesvirus-infected $\mathrm{PKR}^{-1-} \mathrm{MEFs}^{78}$. Therefore, $\mathrm{PKR}$ activation is necessary for the increased autophagy that is seen during infection with $\triangle I C P 34.5$ herpesviruses.

What is the signalling pathway that leads from activated PKR to increased autophagy? MEFs that express only a mutant version of eIF $2 \alpha$ that cannot be phosphorylated showed no increase in autophagy when they were infected with a $\triangle I C P 34.5$ herpesvirus ${ }^{78}$. Therefore, both PKR and a phosphorylatable version of eIF $2 \alpha$ are necessary for the induction of autophagy by herpesvirus; whether they are sufficient is not yet known.

Is autophagy the specific PKR-induced antiviral response that reduces the yield of $\triangle I C P 34.5$ herpesviruses relative to that seen with wild-type viruses, thus indicating that one of the functions of ICP34.5 is to prevent autophagy? By stimulating the dephosphorylation of eIF $2 \alpha$, ICP34.5 should antagonize any downstream effects of eIF $2 \alpha$ phosphorylation by PKR (BOX 1), of which autophagy is as likely a candidate as any other. Indeed, one of the effects of blocking eIF2 $\alpha$ phosphorylation using the inhibitors shown in TABLE 2 might be to inhibit the induction of autophagy.

\section{Autophagy and viruses: subversion}

Some of the first EM analyses of virus-infected cells were performed in the laboratory of George Palade. Studies of cells that were infected with poliovirus (FIG. 4a) showed the presence of large numbers of membranous vesicles with diameters of 200-400 nm, which due to the 'cytoplasmic matrix' present in the lumen of the vesicles - were postulated to "develop by a mechanism comparable to that of the formation of autolytic vesicles"79.

Positive-strand RNA viruses all require membrane surfaces on which to assemble their RNA-replication complexes $^{80,81}$. Several hypotheses have been proposed 


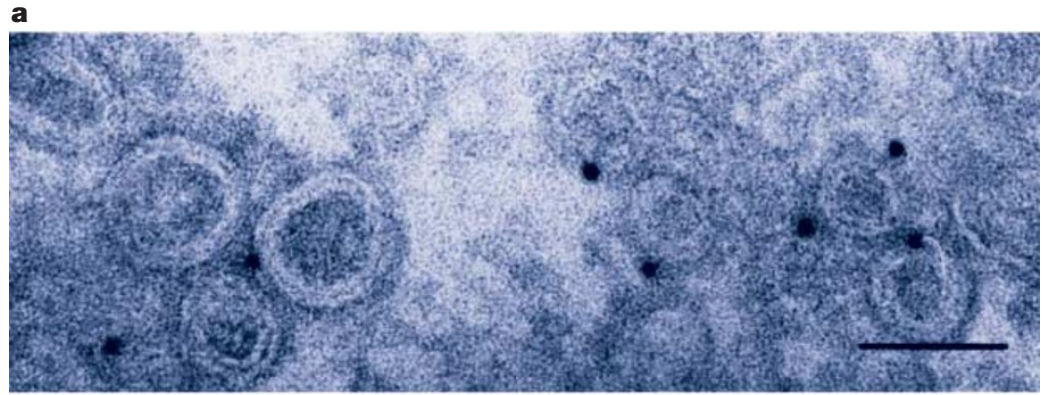

b
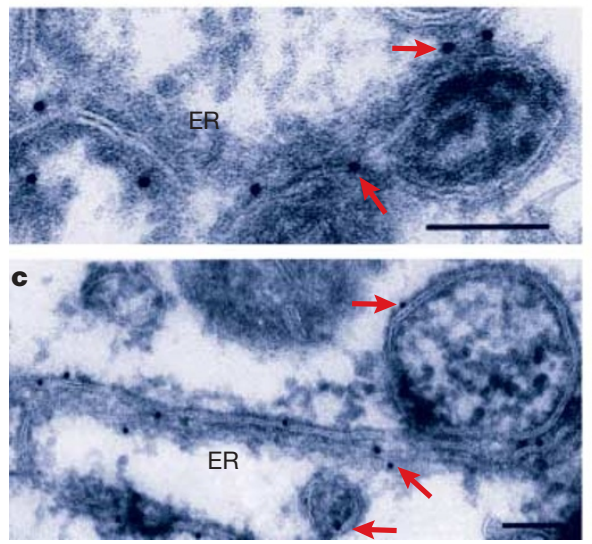

d

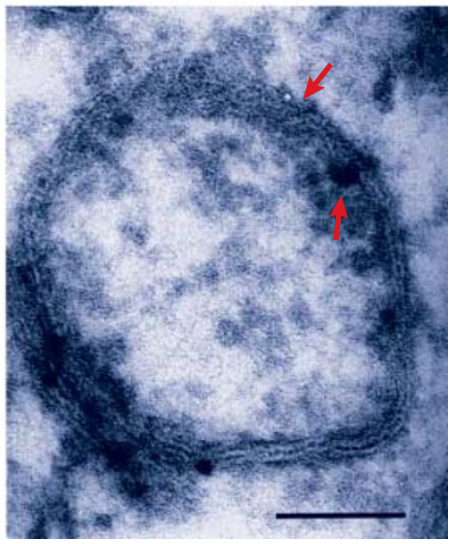

Figure 5 | Formation of double-membrane-bound vesicles during EAV infection and on expression of EAV proteins nsp2 and nsp3. a | RK-13 cells were infected with equine arterivirus (EAV) for $8 \mathrm{~h}$ and cryosections were labelled with anti-nsp2 followed by protein-A-gold detection. Scale bar, $0.1 \mu \mathrm{m}$. b-d | Cryoimmunoelecron microscopy of RK-13 cells in which EAV proteins nsp2 and nsp3 were expressed in precursor forms using a Sindbis virus vector. Gold labelling detects nsp2 (a,c) and nsp3 (d); arrows indicate selected gold particles. Cells were harvested 8-12 h after infection. Scale bars, $0.1 \mu \mathrm{m}$. ER, endoplasmic reticulum. a Reproduced with permission from REF. 94 @ (1999) ASM. b-d Reproduced with permission from REF. $100 @$ (2001) Society for General Microbiology.

COPII

Newly synthesized proteins that are destined for secretion are sorted into vesicles coated with COPII components at endoplasmic-reticulum exit sites. for the origin of these membranes, which include the ER for hepatitis $C$ virus ${ }^{82}$, the outer mitochondrial membrane for flock-house virus ${ }^{83}$ and autophagic membranes for poliovirus (REFS 79,84,85; W. T. J. et al., unpublished observations). Our laboratory has hypothesized that one of the functions of the membrane localization of poliovirus RNA replication complexes is — as has also been suggested for the DNA phage $\Phi 29$ (REFS 86,87) — that intracellular membranes provide a two-dimensional surface on which to assemble the regular oligomeric lattices of viral proteins that are required for cooperative binding to the substrate $\mathrm{RNA}^{88}$.

For a handful of positive-strand viruses, specifically poliovirus, equine arterivirus (EAV) and murine hepatitis virus (MHV), evidence has accumulated that the membranes on which RNA replication complexes form resemble autophagosomes, contain known components of the autophagic pathway, or both. For poliovirus, our laboratory has pursued the original observations of Palade and co-workers to show that the membranes that are induced during poliovirus infection resemble autophagosomes due to the doublemembrane-bound morphology that is present even early in infection (FIG. 4b), their labelling with antiLAMP1 (FIG. 4c) and their low buoyant densities ${ }^{84}$.
Recently, proteins of the poliovirus RNA-replication complex were shown to colocalize with a cotransfected green fluorescent protein (GFP)-LC3 fusion protein, which is a known marker of autophagosomes (TABLE 1). Within 3 hours of poliovirus infection, GFP-LC3 and LAMP1 were shown to colocalize, whereas in uninfected cells no colocalization was seen (W. T. J. et al., unpublished observations). An alternative source for the poliovirus-induced vesicles, however, has been indicated by the presence of the human homologues of the yeast Sec31 and Sec13 proteins, both of which are components of the copi coat of anterograde transport vesicles that bud from the $\mathrm{ER}^{89}$. One possible explanation for this observation might be provided by the finding that, in yeast, mutations in the genes that encode COPII coat proteins lead to defects in autophagy ${ }^{90,91}$. It is therefore possible, although it has not yet been tested, that the COPII proteins are normal components of the autophagic machinery or that they can, under some circumstances, associate with them.

Colocalization of poliovirus RNA-replication complexes with autophagosomes or autophagosomal components might result either from the use of these components by the viral replication complex or the destruction of the viral structures by the autophagic machinery. If the latter scenario were correct, one would expect the pre-induction of autophagy by rapamycin or tamoxifen treatment to reduce viral yield. However, the opposite effect was produced: treatment with either rapamycin or tamoxifen increased poliovirus yield 3-5-fold (W. T. J. et al., unpublished observations). It is therefore likely that the autophagic machinery does not have a destructive role during poliovirus infection and instead contributes to the formation of viral RNA-replication complexes. If the poliovirus-induced membranes are derived from the autophagic pathway, it is probably because of the preponderance of double-membranebound structures that viral products delay the maturation of the autophagosome-like structures into degradative compartments, as has been proposed for Legionella (FIG. 3).

EAV and MHV are both members of the Nidovirales, the order of RNA viruses that includes the recently identified human coronavirus that causes severe acute respiratory syndrome (SARS). During infection with EAV, MHV or the SARS coronavirus, membranous vesicles that are bounded by double lipid bilayers accumulate ${ }^{92-95}$. In EAV-infected cells (FIG. 5a), these vesicles were found to be $80-100 \mathrm{~nm}$ in diameter ${ }^{94}$, whereas MHV-infected cells contained double-membrane-bound vesicles that were closer in size to those seen in poliovirus-infected cells, with a diameter of 200-350 nm (REF. 93). Immunoelectron microscopy showed that proteins of the RNA-replication complexes and newly synthesized, bromouridinelabelled RNA were found in direct association with the double-membrane-bound vesicles ${ }^{93,94,96,97}$.

In the case of MHV, the presence of cellular markers on the virally induced membranes is consistent with their derivation from the autophagic pathway: late 


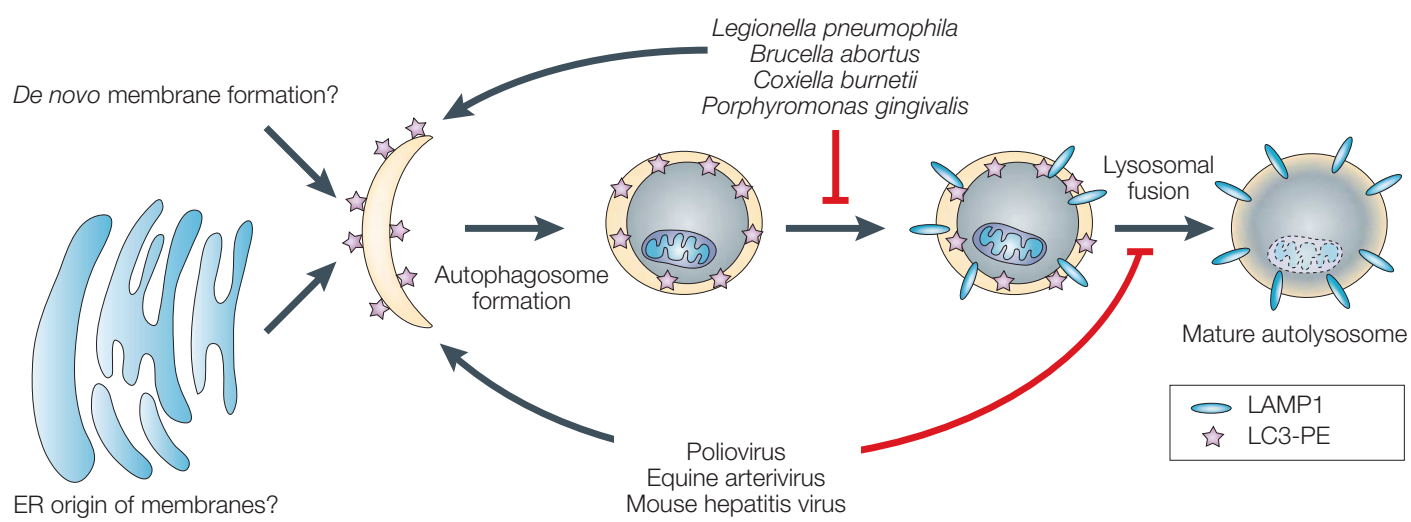

Figure 6 | Potential subversion of the autophagic pathway or its components by bacteria and viruses. Proposed stages at which intracellular bacteria and viruses might induce or interfere with autophagosome development. The viruses and bacteria listed induce the formation of double-membrane-bound compartments that bear markers from the autophagic pathway. The persistence of the double-membrane-bound morphology of these structures indicates that, if they are similar to autophagosomes, their maturation into autolysosomes is arrested. In Legionella, membranes show delayed acquisition of lysosome-associated membrane protein 1 (LAMP1), whereas the poliovirus-induced membranes contain LAMP1; therefore, Legionella and poliovirus are proposed to block autophagic maturation at different steps. ER, endoplasmic reticulum; LC3, microtubule-associated-protein light-chain 3; $\mathrm{PE}$, phosphatidylethanolamine.

endosomal proteins and LC3 were both found to colocalize with viral RNA-replication proteins on these membranes ${ }^{98,99}$. In addition, the degradation of longlived proteins increased from $1.3 \%$ to $2 \%$ in infected cells $^{98}$. Importantly, the yield of extracellular virus was diminished 1000-fold in clonal isolates of $\mathrm{Atg}^{-5^{--}}$mouse embryonic stem cells and the wild-type yield was restored by plasmids that express Atg5 (REF. 98). The reduction in viral yield in the absence of a crucial component of the autophagic machinery clearly indicates that this pathway does not function primarily to degrade this virus. Instead, this strongly indicates that wild-type Atg5 is required for the formation of infectious MHV virions, either as a host factor that is directly involved in this process or, assuming that its only function in mammalian cells is in the autophagy pathway, by allowing the formation of autophagic membranes, presumably to function as a platform for RNA replication. Such a spectacular reduction in yield as a result of eliminating the presence of a certain type of membrane within an infected cell is, perhaps, surprising. When the RNA-replication complex of flock-house virus, a positive-strand RNA virus that can replicate its genome in S. cerevisiae, was re-directed from its normal mitochondrial location to the ER, the efficiency of RNA replication, instead of being reduced, was increased sixfold ${ }^{84}$. It will be of great interest to determine the reason for the strong requirement for Atg5 in the production of extracellular MHV. This might be because Atg5 has a direct role in this process, because it helps to induce autophagic membranes, or because of some other function of Atg5.

The systematic expression of viral proteins individually and in combination has identified the first virally encoded molecular inducers of the formation of doublemembrane-bound vesicles: the poliovirus proteins $2 \mathrm{BC}$ and $3 \mathrm{~A}$ and the EAV proteins nsp 2 and nsp3. FIGURE 5 compares the ultrastructure and immunostaining of membranes that are induced during EAV infection (FIG. 5a) and in the presence of the EAV proteins nsp2 and nsp3 (FIG. 5b-d) ${ }^{100}$. Similarly, poliovirus-infected cells were found to have morphologies similar to those of cells that express only the viral proteins $2 \mathrm{BC}$ and $3 \mathrm{~A}^{84}$. Membranes that are formed in the presence of $2 \mathrm{BC}$ and $3 \mathrm{~A}$ also resemble those that are formed in poliovirusinfected cells in terms of their low buoyant density and their staining with both LC3 and LAMP1, as visualized by immunofluorescence (W. T. J. et al., unpublished observations).

The mechanism by which RNA-virus proteins induce double-membrane-bound vesicles using components of the autophagic pathway is not yet known. An understanding of the disparate sizes of the vesicles that are induced by different viruses, and by the autophagic pathway itself, will await the identification of the proteins that confer membrane curvature. Both EAV proteins, as well as poliovirus $2 \mathrm{C}$, contain nucleoside $5^{\prime}$-triphosphate (NTP)-binding motifs ${ }^{101}$. Curiously, the ultrastructure of cells that express both poliovirus $3 \mathrm{~A}$ and $2 \mathrm{C}$, but not the precursor $2 \mathrm{BC}$, strongly resembles that of MHV-infected $\mathrm{Atg} 5^{-1-}$ cells, with apparently ER-derived membranes that contain cytoplasmic invaginations ${ }^{84,98}$. It is tempting to speculate that these structures represent intermediates in membranous-vesicle formation, in which membranes have invaginated but have not resolved into autonomous vesicles.

\section{Summary}

As shown schematically in FIG. 6, several different intracellular bacteria and positive-strand RNA viruses have been suggested to both stimulate the accumulation of membranes that bear autophagic markers and to inhibit their maturation. Why do certain viruses and intracellular bacteria use proteins, and possibly membranes, that are derived from the autophagic pathway? 
In the case of bacteria that replicate within compartments that bear features of autophagosomes, this might provide an environment that is cytoplasmic but protected, which shields the bacteria from host responses. It is possible that the viruses and bacteria discussed here use the highly inducible cellular autophagy pathway to proliferate required membranes without triggering cellular defences. The stepwise maturation of the resulting compartments (FIG.2) might allow the fine-tuning of the $\mathrm{pH}$, or the protein or lipid composition, depending on which steps are induced or inhibited (FIG. 6). Finally, the cytoplasmic lumens of double-membrane-bound vesicles that are formed during poliovirus infection, for example, sometimes contain progeny virions (FIG. 4a). These vesicles are likely to be those that are formed late in infection, so that the engulfed cytoplasm already contains mature viral particles. These virions may be destined for destruction by bona fide autophagy. However, it is also possible that the unique topology of double-membrane-bound vesicles allows a certain amount of extracellular delivery of obligate intracellular microorganisms without cell lysis. Infectious poliovirus is known to be able to exit from the apical surface of polarized cell monolayers without a breach in the integrity of the epithelial sheet $^{102}$; the mechanism of such documented examples of non-lytic cell exit by this and other 'lytic' viruses is not yet known.

The interactions between the autophagic pathway and the infectious cycles of intracellular bacteria and viruses are complex. Many microorganisms are undoubtedly engulfed during the destructive process of autophagosome formation and maturation into autolysosomes. It is also likely that successful microorganisms, such as the viruses that have evolved to inhibit eIF2 $\alpha$ phosphorylation by PKR, can at least partially avoid this destruction. Several bacteria and viruses seem to use components of the autophagic pathway to facilitate their replication. Understanding the mechanisms by which autophagic components are usurped by microorganisms and the molecules that are involved in this might be instrumental in dissecting the process of cellular autophagy, as well as in its subversion.

\section{Note added in proof}

Recently, a genetic screen has identified multiple novel protein substrates of the Legionella pneumophila dot/icm translocation apparatus, all of which are potential candidates for the molecular effectors of the host-membrane rearrangements that accompany Legionella infection. See REF. 128 for details.
1. Stromhaug, P. E. \& Klionsky, D. J. Approaching the molecular mechanism of autophagy. Traffic 2, 524-531 (2001). An excellent review that emphasizes the relationship between autophagy and other membane-trafficking pathways, as illuminated by yeast genetics.

2. Klionsky, D. J. et al. A unified nomenclature for yeast autophagy-related genes. Dev. Cell 5, 539-545 (2003). Essential for the decoding of any pre-2003 autophagy literature, as a very helpful table both gives current and all previous - names for the genes that are required for autophagy in S. cerevisiae and describes their homologues in other organisms.

3. Liang, X. H. et al. Induction of autophagy and inhibition of tumorigenesis by beclin 1. Nature 402, 672-676 (1999).

4. Melendez, A. et al. Autophagy genes are essential for dauer development and life-span extension in C. elegans. Science 301, 1387-1391 (2003).

5. Otto, G. P., Wu, M. Y., Kazgan, N., Anderson, O. R. \& Kessin, R. H. Macroautophagy is required for multicellular development of the social amoeba Dictyostelium discoideum. J. Biol. Chem. 278, 17636-17645 (2003).

6. Doelling, J. H., Walker, J. M., Friedman, E. M., Thompson, A. B. \& Vierstra, R. D. The APG8/12-activating enzyme APG7 is required for proper nutrient recycling and senescence in Arabidopsis thaliana. J. Biol. Chem. 277, 33105-33114 (2002).

7. Hanaoka, H. et al. Leaf senescence and starvation-induced chlorosis are accelerated by the disruption of an Arabidopsis autophagy gene. Plant Physiol. 129 1181-1193 (2002)

8. Smith, J. D. \& de Harven, E. Herpes simplex virus and human cytomegalovirus replication in WI-38 cells. J. Virol. 26, 102-109 (1978).

9. Guidotti, L. G. et al. Viral clearance without destruction of infected cells during acute HBV infection. Science $\mathbf{2 8 4}$, 825-829 (1999).

10. Schaible, U. E. et al. Parasitophorous vacuoles of Leishmania mexicana acquire macromolecules from the host cell cytosol via two independent routes. J. Cell Sci. 112, 681-693 (1999).

11. Swanson, M. S. \& Fernandez-Moreia, E. A microbia strategy to multiply in macrophages: the pregnant pause. Traffic 3, 170-177 (2002).

12. Kuma, A., Mizushima, N., Ishihara, N. \& Ohsumi, Y. Formation of the approximately $350-\mathrm{kDa}$ Apg12-Apg5-Apg16 multimeric complex, mediated by Apg16 oligomerization, is essential for autophagy in yeast. J. Biol. Chem. 277, 18619-18625 (2002).
13. Stromhaug, P. E., Berg, T. O., Fengsrud, M. \& Seglen, P. O. Purification and characterization of autophagosomes from rat hepatocytes. Biochem. J. 335, 217-224 (1998). Demonstrates the purification and analysis of autophagosomes using reliable assays for monitoring their purity and integrity.

14. Kopitz, J., Kisen, G. O., Gordon, P. B., Bohley, P. \& Seglen, P. O. Nonselective autophagy of cytosolic enzymes by isolated rat hepatocytes. J. Cell Biol. 111, 941-953 (1990).

15. Mitchener, J. S., Shelburne, J. D., Bradford, W. D. \& Hawkins, H. K. Cellular autophagocytosis induced by deprivation of serum and amino acids in HeLa cells. Am. $J$. Pathol. 83, 485-491 (1976).

16. Dunn, W. A. Jr. Studies on the mechanisms of autophagy: formation of the autophagic vacuole. J. Cell Biol. 110, 1923-1933 (1990).

Ground-breaking ultrastructural and biochemical description of the stages of autophagosome formation.

17. Mizushima, N. et al. Dissection of autophagosome formation using Apg5-deficient mouse embryonic stem cells. J. Cell Biol. 152, 657-668 (2001).

The first publication to describe the effects of homozygous mutation of a gene identified in yeast for its role in autophagy; this paper is crucial for understanding the role of Atg5 in autophagosome formation in mammalian cells.

18. Cutler, N. S., Heitman, J. \& Cardenas, M. E. TOR kinase homologs function in a signal transduction pathway that is conserved from yeast to mammals. Mol. Cell. Endocrinol. 155, 135-142 (1999).

19. Bursch, W. et al. Autophagic and apoptotic types of programmed cell death exhibit different fates of cytoskeletal filaments. J. Cell Sci. 113, 1189-1198 (2000).

20. Ogier-Denis, E., Bauvy, C., Houri, J. \& Codogno, P. Evidence for a dual control of macroautophagic sequestration and intracellular trafficking of $N$-linked glycoproteins by the trimeric $\mathrm{G}_{13}$ protein in $\mathrm{HT}-29$ cells. Biochem. Biophys. Res. Commun. 235, 166-170 (1997).

21. Petiot, A., Ogier-Denis, E., Blommaart, E. F., Meijer, A. J. \& Codogno, P. Distinct classes of phosphatidylinositol 3kinases are involved in signaling pathways that control macroautophagy in HT-29 cells. J. Biol. Chem. $\mathbf{2 7 5}$, 992-998 (2000).

A well-written, informative paper that uses long-lived protein degradation, PI3K inhibitors and the effects of individual phospholipids to argue that type III PI3Ks are positive regulators of autophagy.
22. Pattingre, S., Bauvy, C. \& Codogno, P. Amino acids interfere with the ERK1/2-dependent control of macroautophagy by controlling the activation of Raf- 1 in human colon cancer HT-29 cells. J. Biol. Chem. 276, 16667-16674 (2003).

23. Holen, I., Gordon, P. B. \& Seglen, P. O. Inhibition of hepatocytic autophagy by okadaic acid and other protein phosphatase inhibitors. Eur. J. Biochem. 215, 113-122 (1993).

24. Mizushima, N., Sugita, H., Yoshimori, T. \& Ohsumi, Y. A new protein conjugation system in human. J. Biol. Chem. 273 33889-33892 (1998)

25. Ohsumi, Y. Molecular dissection of autophagy: two ubiquitin-like systems. Nature Rev. Mol. Cell Biol. 2 , 211-216 (2001).

An insightful review that details the events of Atg5-Atg12 and LC3-PE conjugation and their role in autophagosome formation.

26. Mizushima, N. et al. A protein conjugation system essentia for autophagy. Nature 395, 395-398 (1998). A landmark paper that describes the covalent modification cascades that occur early in autophagosome formation.

27. Mizushima, N., Yoshimori, T. \& Ohsumi, Y. Mouse Apg10 as an Apg12 conjugating enzyme: analysis by the conjugationmediated yeast two-hybrid method. FEBS Lett. 532 450-454 (2002)

28. Tanida, I., Tanika-Miyaki, E., Komatsu, M., Ueno, T. \& Kominami, E. The human homolog of Saccharomyces cerevisiae Apg7p is a protein-activating enzyme for multiple substrates including human Apg12p, GATE-16, GABARAP, and MAP-LC3. J. Biol. Chem. 276, 1701-1706 (2002)

29. Kabeya, Y. et al. LC3, a mammalian homologue of yeast Apg8p, is localized in autophagosome membranes after processing. EMBO J. 19, 5720-5728 (2000). Describes the processing of LC3 during autophagic induction and makes a convincing case to indicate that LC3 lipidation and localization are the best markers for autophagic structures.

30. Punnonen, E. L., Autio, S., Marjomaki, V. S. \& Reunanen, H. Autophagy, cathepsin $\mathrm{L}$ transport, and acidification in cultured rat fibroblasts. J. Histochem. Cytochem. $\mathbf{4 0}$ 1579-1587 (1992).

31. Nuoffer, C. \& Balch, W. E. GTPases: multifunctional molecular switches regulating vesicular traffic. Annu. Rev. Biochem. 63, 949-990 (1994).

32. Munafo, D. B. \& Colombo, M. I. Induction of autophagy causes dramatic changes in the subcellular distribution of GFP-Rab24. Traffic 3, 472-482 (2002). 
33. Munafo, D. B. \& Colombo, M. I. A novel assay to study autophagy: regulation of autophagosome vacuole size by amino acid deprivation. J. Cell Sci. 114, 3619-3629 (2001).

34. Beron, W., Gutierrez, M. G., Rabinovitch, M. \& Colombo, M. I. Coxiella burnetii localizes in a Rab7-labeled compartment with autophagic characteristics. Infect. Immun. $\mathbf{7 0}$, 5816-5821 (2002)

35. Biederbick, A., Kern, H. F. \& Elsasser, H. P. Monodansylcadaverine (MDC) is a specific in vivo marker for autophagic vacuoles. Eur. J. Cell Biol. 66, 3-14 (1995). The first paper to describe the use of MDC as a marker of autophagosomes; also briefly discusses the requirement for fixation for the specificity of this marker.

36. Seglen, P. O. \& Gordon, P. B. Amino acid control of autophagic sequestration and protein degradation in isolated rat hepatocytes. J. Cell Biol. 99, 435-444 (1984).

37. Kobayashi, H., Sunako, M., Hayashi, M. \& Murooka, Y. DNA synthesis and fragmentation in bacteroids during Astragalus sinicus root nodule development. Biosci. Biotechnol. Biochem. 65, 510-515 (2001).

Shows that the symbiont Mesorhizobium huakuil encounters different intracellular fates in the plant Astragalus sinicus depending on nutrient conditions; during nutrient starvation, the bacterium is destroyed by its host in vacuoles that resemble autophagosomes.

38. Rikihisa, Y. Glycogen autophagosomes in polymorphonuclear leukocytes induced by rickettsiae. Anat. Rec. 208, 319-327 (1984).

39. Turco, J. \& Winkler, H. H. Role of the nitric oxide synthase pathway in inhibition of growth of interferon-sensitive and interferon-resistant Rickettsia prowazekii strains in L929 cells treated with tumor necrosis factor- $\alpha$ and $\gamma$-interferon. Infect. Immun. 61, 4317-4325 (1993).

40. Turco, J., Liu, H., Gottlieb, S. F. \& Winkler, H. H. Nitric oxidemediated inhibition of the ability of Rickettsia prowazekii to infect mouse fibroblasts and mouse macrophage-like cells. Infect. Immun. 66, 558-566 (1998).

41. Feng, H. M., Wen, J. \& Walker, D. H. Rickettsia australis infection: a murine model of a highly invasive vasculopathic rickettsiosis. Am. J. Pathol. 142, 1471-1482 (1993).

42. Walker, D. H., Popov, V. L., Crocquet-Valdes, P. A. Welsh, C. J. \& Feng, H. M. Cytokine-induced, nitric oxidedependent, intracellular antirickettsial activity of mouse endothelial cells. Lab. Invest. 76, 129-138 (1997). Shows an interesting correlation between intracellular nitric-oxide concentrations, Rickettsia conorii growth and the presence of apparently autophagic structures.

43. Rich, K. A., Burkett, C. \& Webster, P. Cytoplasmic bacteria can be targets for autophagy. Cell. Microbiol. 5, 455-468 (2003)

44. Hersh, D. et al. The Salmonella invasin SipB induces macrophage apoptosis by binding to caspase-1. Proc. Nat Acad. Sci. USA 96, 2396-2401 (1999).

45. Hernandez, L. D., Pypaert, M., Flavell, R. A. \& Galan, J. E. A Salmonella protein causes macrophage cell death by inducing autophagy. J. Cell Biol. 163, 1123-1131 (2003).

46. Progulske-Fox, A. et al. Porphyromonas gingivalis virulence factors and invasion of cells of the cardiovascular system. J. Periodontal. Res. 34, 393-399 (1999).

47. Dorn, B. R., Dunn, W. A. Jr \& Progulske-Fox, A. Porphyromonas gingivalis traffics to autophagosomes in human coronary artery endothelial cells. Infect. Immun. 69 5698-5708 (2001).

48. Pizarro-Cerda, J. et al. Brucella abortus transits through the autophagic pathway and replicates in the endoplasmic reticulum of nonprofessional phagocytes. Infect. Immun. $\mathbf{6 6}$ 5711-5724 (1998)

49. Pizarro-Cerda, J., Moreno, E., Sanguedolce, V., Mege, J. L. \& Gorvel, J. P. Virulent Brucella abortus prevents lysosome fusion and is distributed within autophagosome-like compartments. Infect. Immun. 66, 2387-2392 (1998).

50. Comerci, D. J., Martinez-Lorenzo, M. J., Sieira, R., Gorvel, J. P. \& Ugalde, R. A. Essential role of the VirB machinery in the maturation of the Brucella abortuscontaining vacuole. Cell. Microbiol. 3, 159-168 (2001)

51. Delrue, R. M. et al. Identification of Brucella spp. genes involved in intracellular trafficking. Cell. Microbiol. 3, 487-497 (2001).

52. Dorn, B. R., Dunn, W. A. Jr \& Progulske-Fox, A. Bacterial interactions with the autophagic pathway. Cell. Microbiol. 4 1-10 (2002).

53. Sturgill-Koszycki, S. \& Swanson, M. S. Legionella pneumophila replication vacuoles mature into acidic, endocytic organelles. J. Exp. Med. 192, 1261-1272 (2000).

54. Swanson, M. S. \& Isberg, R. R. Association of Legionella pneumophila with the macrophage endoplasmic reticulum. Infect. Immun. 63, 3609-3620 (1995).
55. Joshi, A. D., Sturgill-Koszycki, S. \& Swanson, M. S. Evidence that Dot-dependent and -independent factors solate the Legionella pneumophila phagosome from the endocytic network in mouse macrophages. Cell. Microbiol. 3, 99-114 (2001).

Virulent wild-type $L$. pneumophila were found in a compartment that shows several characteristics of an autophagosome and is distinct from the compartments that surround type-IV-secretionmutant or heat-killed bacteria.

56. Coers, J. et al. Identification of Icm protein complexes that play distinct roles in the biogenesis of an organelle permissive for Legionella pneumophila intracellular growth. Mol. Microbiol. 38, 719-736 (2000).

57. Berger, K. H. \& Isberg, R. R. Two distinct defects in intracellular growth complemented by a single genetic locus in Legionella pneumophila. Mol. Microbiol. 7, 7-19 (1993).

58. Berger, K. H., Merriam, J. J. \& Isberg, R. R. Altered intracellular targeting properties associated with mutations in the Legionella pneumophila dotA gene. Mol. Microbiol. 14 809-822 (1994).

59. Marra, A., Blander, S. J., Horwitz, M. A. \& Shuman, H. A. Identification of a Legionella pneumophila locus required for intracellular multiplication in human macrophages. Proc. Natl Acad. Sci. USA 89, 9607-9611 (1992).

60. Sexton, J. A. \& Vogel, J. P. Type IVB secretion by intracellular pathogens. Traffic 3, 178-185 (2002).

61. Vogel, J. P., Andrews, H. L., Wong, S. K. \& Isberg, R. R. Conjugative transfer by the virulence system of Legionella pneumophila. Science 279, 873-876 (1998).

62. Nagai, H., Kagan, J. C., Zhu, X., Kahn, R. A. \& Roy, C. R. A bacterial guanine nucleotide exchange factor activates ARF on Legionella phagosomes. Science 295, 679-682 (2002).

63. Tilney, L. G., Harb, O. S., Connely, P. S., Robinson, C. G. \& Roy, C. R. How the parasitic bacterium Legionella pneumophila modifies its phagosome and transforms it into rough ER: implications for conversion of plasma membrane to the ER membrane. J. Cell Sci. 114, 4637-4650 (2001).

64. Kagan, J. C. \& Roy, C. R. Legionella phagosomes intercept vesicular traffic from endoplasmic reticulum exit sites. Nature Cell Biol. 4, 945-954 (2002).

65. Otto, G. P. et al. Macroautophagy is dispensable for intracellular replication of Legionella pneumophila in Dictyostelium discoideum. Mol. Microbiol. 51, 63-72 (2004). One of the first papers in which knock-outs of genes that are essential for autophagy were used to determine the role of autophagic processes in microbial infection. In this case, autophagy is not required either for growth or for the characteristic morphology induced by Legionella infection of Dictyostelium.

66. Akporiaye, E. T., Rowatt, J. D., Aragon, A. A. \& Baca, O. G. Lysosomal response of a murine macrophage-like cell line persistently infected with Coxiella burnetii. Infect. Immun. $\mathbf{4 0}$ 1155-1162 (1983)

67. Chen, S. Y., Vodkin, M., Thompson, H. A. \& Williams, J. C. Isolated Coxiella burnetii synthesizes DNA during acid activation in the absence of host cells. J. Gen. Microbio. 136, 89-96 (1990).

68. Burton, P. R., Stueckemann, J., Welsh, R. M. \& Paretsky, D. Some ultrastructural effects of persistent infections by the rickettsia Coxiella burnetii in mouse $L$ cells and green monkey kidney (Vero) cells. Infect. Immun. 21, 556-566 (1978).

69. Hackstadt, T. \& Williams, J. C. Biochemical stratagem for obligate parasitism of eukaryotic cells by Coxiella burnetii. Proc. Natl Acad. Sci. USA 78, 3240-3244 (1981).

70. Heinzen, R. A., Hackstadt, T. \& Samuel, J. E. Developmenta biology of Coxiella burnetii. Trends Microbiol. 7, 149-154 (1999).

71. Heinzen, R. A., Scidmore, M. A., Rockey, D. D. \& Hackstadt, T. Differential interaction with endocytic and exocytic pathways distinguish parasitophorous vacuoles of Coxiella burnetii and Chlamydia trachomatis. Infect. Immun. 64 796-809 (1996).

72. Zamboni, D. S., McGrath, S., Rabinovitch, M. \& Roy, C. R Coxiella burnetii express type IV secretion system proteins that function similarly to components of the Legionella pneumophila Dot/lcm system. Mol. Microbiol. 49, 965-976 (2003).

73. Papini, E., Zoratti, M. \& Cover, T. L. In search of the Helicobacter pylori VacA mechanism of action. Toxicon 39 1757-1767 (2001).

74. Molinari, M. et al. Vacuoles induced by Helicobacter pylori toxin contain both late endosomal and lysosomal markers. J. Biol. Chem. 272, 25339-25344 (1997).

75. Catrenich, C. E. \& Chestnut, M. H. Character and origin of vacuoles induced in mammalian cells by the cytotoxin of Helicobacter pylori. J. Med. Microbiol. 37, 389-395 (1992).
76. Leib, D. A., Machalek, M. A., Williams, B. R., Silverman, R. H. \& Virgin, H. W. Specific phenotypic restoration of an attenuated virus by knockout of a host resistance gen Proc. Natl Acad. Sci. USA 97, 6097-6101 (2000).

A rigorously performed set of experiments, using both viral and host mutant genomes, which makes it clear that the function of the herpesvirus ICP47.5 gene is to counteract the antiviral effects of the cellular dsRNAactivated protein kinase, PKR.

77. Williams, B. R. Signal integration via PKR. Sci. STKE 2001 $<$ http://stke.sciencemag.org/cgi/content/full/OC_sigtrans;2 001/89/re2> (2001)

78. Talloczy, Z. et al. Regulation of starvation- and virus-induced autophagy by the elF2 $\alpha$ kinase signaling pathway. Proc. Natl Acad. Sci. USA 99, 190-195 (2002).

Clearly shows that the antiviral function of the cellular dsRNA-activated protein kinase, PKR, is exerted through its phosphorylation of elF2 $\alpha$ and that this correlates with autophagic induction.

79. Dales, S., Eggers, H. J., Tamm, I. \& Palade, G. E. Electron microscopic study of the formation of poliovirus. Virology $\mathbf{2 6}$, 379-389 (1965)

Exquisite electron micrographs from the laboratory of the grandfather of cell biology clearly showed doublemembrane-bound vesicles in poliovirus infection, with examples of virions found within the cytoplasmic lumen.

80. Bienz, K., Egger, D., Pfjister, T. \& Troxler, M. Structural and functional characterization of the poliovirus replication complex. J. Virol. 66, 2740-2747 (1992).

81. Bolton, R. et al. Intracellular localization of poliovirus plusand minus-strand RNA visualized by strand-specific fluorescent in situ hybridization. J. Virol. 72, 8578-8585 (1998).

82. Dubuisson, J., Penin, R. \& Moradpour, D. Interactions of hepatitis $C$ virus proteins with host cell membranes and lipids. Trends Cell. Biol. 12, 517-523 (2002).

83. Miller, D. J., Schwartz, M. D., Dye, B. T. \& Ahlquist, P. Engineered retargeting of viral RNA replication complexes to an alternative intracellular membrane. J. Virol. 77, 12193-12202 (2003)

The re-targeting of the RNA-replication complex from a positive-strand virus from the mitochondial membrane to the ER of S. cerevisae was shown to increase RNA yield, even though the site of RNA replication in the normal hosts of the virus is the mitochondrial membrane.

84. Suhy, D. A., Giddings, T. H. Jr \& Kirkegaard, K. Remodeling the endoplasmic reticulum by poliovirus infection and by individual viral proteins: an autophagy-like origin for virusinduced vesicles. J. Virol. 74, 8953-8965 (2000). Two individual viral proteins expressed in isolation were shown to induce double-membrane-bound vesicles with similar ultrastructural and biochemical characteristics to autophagosomes, and to the membranes that proliferate during viral infection

85. Schlegel, A., Giddings, T. H., Ladinsky, M. S. \& Kirkegaard, K. Cellular origin and ultrastructure of membranes induced during poliovirus infection. J. Virol. 70, 6576-6588 (1996)

86. Bravo, A. \& Salas, M. Polymerization of bacteriophage F29 replication protein 11 into protofilament sheets. EMBO J. 17, 6096-6105 (1998).

87. Serrano-Heras, G., Salas, M. \& Bravo, A. In vivo assembly of phage F29 replication protein $\mathrm{p} 1$ into membrane-associated multimeric structures. J. Biol. Chem. 278, 40771-40777 (2003)

88. Lyle, J. M., Bullitt, E., Bienz, K. \& Kirkegaard, K. Visualization and functional analysis of RNA-dependent RNA polymerase lattices Science 296, 2218-2222 (2002).

89. Rust, R. C. et al. Cellular COPIl proteins are involved in production of the vesicles that form the poliovirus replication complex. J. Virol. 75, 9808-9818 (2001).

90. Hamasaki, M., Noda, T. \& Ohsumi, Y. The early secretory pathway contributes to autophagy in yeast. Cell Struct. Funct. 28, 49-54 (2003).

91. Ishihara, N. et al. Autophagosome requires specific early Sec proteins for its formation and NSF/SNARE for vacuolar fusion. Mol. Biol. Cell 12, 3690-3702 (2001).

92. Dubois-Dalcq, M., Holmes, K. V. \& Rentier, B. Assembly of Enveloped RNA Viruses (Springer Verlag, Vienna, 1984).

93. Gosert, R., Kanjanahaluethai, A., Egger, D., Bienz, K. \& Baker, S. C. RNA replication of mouse hepatitis virus takes place at double-membrane vesicles. J. Virol. 76, 3697-3708 (2002).

94. Pederson, K. W., van der Meer, Y., Roos, N. \& Snijder, E. J. Open reading frame $1 \mathrm{a}$-encoded subunits of the arterivirus replicase induce endoplasmic reticulum-derived doublemembrane vesicles which carry the viral replication complex. J. Virol. 73, 2016-2026 (1999). 
95. Goldsmith, C. S. et al. Ultrastructural characterization of SARS coronavirus. Emerg. Infect. Dis. 10, 320-326 (2004)

96. Shi, S. T. et al. Colocalization and membrane assocation of murine hepatitis virus gene 1 products and de novosynthesized viral RNA in infected cells. J. Virol. 73 5957-5969 (1999).

97. van der Meer, Y., van Tol, H., Locker, J. K. \& Snijder, E. J. ORF1a-encoded replicase subunits are involved in the membrane association of the arterivirus replication complex. J. Virol. 72, 6689-6698 (1998).

98. Prentice, E., Jerome, W. G., Yoshimori, T., Mizushima, N. \& Denison, M. R. Coronavirus replication complex formation utilizes components of cellular autophagy. J. Biol. Chem. 2003 Dec 29 [Epub ahead of print].

Demonstrates the first use of mammalian-host genetics to investigate the role of a gene required for autophagy, APG5, in RNA-virus replication; in the absence of the gene, a 1000-fold decrease in the yield of extracellular virus was found.

99. van der Meer, Y. et al. Localization of mouse hepatitis virus nonstructural proteins and RNA synthesis indicate a role for late endosomes in viral replication. J. Virol. 73, 7641-7657 (1999)

100. Snijder, E. J., van Tol, H., Roos, N. \& Pedersen, K. W. Nonstructural proteins 2 and 3 interact to modify host cell membranes during the formation of the arterivirus replication complex. J. Gen. Virol. 82, 985-994 (2001).

Two individual viral proteins, expressed in isolation were shown to induce membranes with ultrastructural characteristics of autophagosomes and of the structures that are induced during viral infection.

101. Gorbalenya, A. E., Koonin, E. V., Donchenko, A. P. \& Blinov, V. M. An NTP-binding motif is the most conserved sequence in a highly diverged monophyletic group of proteins involved in positivestrand RNA viral replication. J. Mol. Evol. 28, 256-268 (1989).

102. Tucker, S. P., Thornton, C. L., Wimmer, E. \& Compans, R. W. Vectorial release of poliovirus from polarized human intestinal epithelial cells. J. Virol. $\mathbf{6 7}$ 4274-4282 (1993).

103. Kaufman, R. J. in Translational Control of Gene Expression (eds Sonenberg, N., Hershey, J. W. B. \& Mathews, M. B.) 503-527 (Cold Spring Harbor Laboratory Press, Cold Spring Harbor, 2000).

104. Harding, H. P Z Zhang, Y, Bertolotti, A, Zeng, H \& Ron, D. Perk is essential for translational regulation and cell survival during the unfolded protein response. Mol. Cell 5, 897-904 (2000).

105. Scheuner, D. et al. Translational control is required for the unfolded protein response and in vivo glucose homeostasis. Mol. Cell 7, 1165-1176 (2001)

106. He, B., Gross, M. \& Roizman, B. The $\gamma_{1} 34.5$ protein of herpes simplex virus 1 has the structural and functional attributes of a protein phosphatase 1 regulatory subunit and is present in a high molecular weight complex with the enzyme in infected cells. J. Biol. Chem. 273, 20727-20743 (1998)
107. Poppers, J., Mulvey, M., Khoo, D. \& Mohr, I. Inhibition of PKR activation by the proline-rich RNA binding domain of the herpes simplex virus type 1 Us 11 protein. J. Virol. 74, 11215-11221 (2000).

108. Stark, G. R., Kerr, I. M., Williams, B. R. G., Silverman, R. H. \& Schreiber, R. D. The vaccinia virus E3L gene product interacts with both the regulatory and the substrate binding regions of PKR: implications for PKR autoregulation. Virology 250, 302-325 (1998).

109. Gonzalez-Lopez, C., Martinez-Costas, J., Esteban, M. \& Benavente, J. Evidence that avian reovirus $\sigma A$ protein is an inhibitor of the double-stranded RNA-dependent protein kinase. J. Gen. Virol. 84, 1629-1639 (2003).

110. Lloyd, R. M. \& Shatkin, A. J. Translational stimulation by reovirus polypeptide $\sigma 3$ : substitution for VAI RNA and inhibition of phosphorylation of the $\alpha$ subunit of eukaryotic initiation factor 2. J. Virol. 66, 6878-6884 (1992).

111. Lu, Y., Wambach, M., Katze, M. G. \& Krug, R. M. Binding of the influenza virus NS1 protein to double-stranded RNA inhibits the activation of the protein kinase that phosphorylates the elF-2 translation initiation factor. Virology 214, 222-228 (1995)

112. Poppers, J., Mulvey, M., Perez, C., Khoo, D. \& Mohr, I. Identification of a lytic-cycle Epstein-Barr virus gene product that can regulate PKR activation. J. Virol. 77, 228-236 (2003).

113. Patel, G. \& Jones, N. C. Activation in vitro of RNA polymerase II and III directed transcription by baculovirus produced E1A protein. Nucleic Acids Res. 18, 2909-2915 (1990).

114. Clemens, M. J. et al. Regulation of the interferon-inducible elF- $2 \alpha$ protein kinase by small RNAs. Biochimie 76 770-778 (1994).

115. Gunnery, S. \& Mathews, M. B. RNA binding and modulation of PKR activity. Methods 15, 189-198 (1998).

116. Gunnery, S., Rice, A. P., Robertson, H. D. \& Mathews, M. B. Tat-responsive region RNA of human immunodeficiency virus 1 can prevent activation of the double-stranded-RNAactivated protein kinase. Proc. Natl Acad. Sci. USA 87, 8687-8691 (1990)

117. Tan, S. L. \& Katze, M. G. Biochemical and genetic evidence for complex formation between the influenza A virus NS1 protein and the interferon-induced PKR protein kinase. J. Interferon Cytokine Res. 18, 757-766 (1998).

118. Bilgin, D. D., Liu, Y., Schiff, M. \& Dinesh-Kumar, S. P. P58 $8^{\mathrm{PK}}$ a plant ortholog of double-stranded RNA-dependent protein kinase PKR inhibitor, functions in viral pathogenesis. Dev. Cell 4, 651-661 (2003)

119. Black, T. L., Safer, B., Hovanessian, A. \& Katze, M. G. The cellular 68,000-Mr protein kinase is highly autophosphorylated and activated yet significantly degraded during poliovirus infection: implications for translational regulation. J. Virol. 63, 2244-2251 (1989).

120. Dever, T. E. et al. Disruption of cellular translational control by a viral truncated eukaryotic translation initiation factor $2 \alpha$ kinase homolog. Proc. Natl Acad. Sci. USA 95, 4164-4169 (1998).

121. Gale, M. J. Jr, Korth, M. J. \& Katze, M. G. Repression of the PKR protein kinase by the hepatitis C virus NS5A protein: a potential mechanism of interferon resistance. Clin. Diagn. Virol. 10, 157-162 (1998).
122. Brand, S. R., Kobayashi, R. \& Mathews, M. B. The Tat protein of human immunodeficiency virus type 1 is a substrate and inhibitor of the interferon-induced, virally activated protein kinase, PKR. J. Biol. Chem. 272, 8388-8395 (1997).

123. Carroll, K., Elroy-Stein, O., Moss, B. \& Jagus, R. Recombinant vaccinia virus $\mathrm{K} 3 \mathrm{~L}$ gene product prevents activation of double-stranded RNA-dependent, initiation factor $2 \alpha$-specific protein kinase. J. Biol. Chem. 268 12837-12842 (1993).

124. Ramelot, T. A. et al. Myxoma virus immunomodulatory protein M156R is a structural mimic of eukaryotic translation initiation factor elF2 $\alpha$. J. Mol. Biol. 322, 943-954 (2002).

125. Esteban, M. et al. The latency protein LANA2 from Kaposi's sarcoma-associated herpesvirus inhibits apoptosis induced by dsRNA-activated protein kinase but not RNase L activation. J. Gen. Virol. 84, 1463-1470 (2003).

126. He, B., Gross, M. \& Roizman, B. The $\gamma_{1} 34.5$ protein of herpes simplex virus 1 complexes with protein phosphatase $1 \alpha$ to dephosphorylate the $\alpha$ subunit of the eukaryotic translation initiation factor 2 and preclude the shutoff of protein synthesis by double-stranded RNAactivated protein kinase. Proc. Natl Acad. Sci. USA 94, 843-848 (1997)

127. Swaminathan, S., Rajan, P., Savinova, O., Jagus, R. \& Thimmapaya, B. Simian virus 40 large-T bypasses the translational block imposed by the phosphorylation of elF-2 $\alpha$. Virology 219, 321-323 (1996)

128. Luo, Z.-Q. \& Isberg, R. R. Multiple substrates of the Legionella pneumophila Dot/lcm system identified by interbacterial protein transfer. Proc. Natl Acad. Sci. USA 101, 841-846 (2004).

Acknowledgements

We thank P. Sarnow and M. Brahic for critical comments on the text, and R. Kopito, T. H. Giddings Jr, P. Codogno, E. Baehrecke and M. Swanson for helpful discussions. The Kirkegaard laboratory is supported by the $\mathrm{NIH}$ and the Ellison Foundation.

Competing interests statement

The authors declare that they have no competing financial interests.

\section{(4) Online links}

\section{DATABASES}

The following terms in this article are linked online to:

Entrez: http://www.ncbi.nlm.nih.gov/entrez

Atg3 | ATG5 |ATG6 | ATG7 | Atg8 | Atg10 |Atg12 |Atg16 | RalF | Sec13 $\mid$ Sec31 $|\mathrm{SipB}|$

LocusLink: http://www.ncbi.nlm.nih.gov/LocusLink ARF1 | beclin $1 \mid$ caspase 1 | cathepsin D | cathepsin L | elF2 $\alpha$ LAMP1 | LAMP2| LC3 | NF-KB | PKR | SAR1 | SEC7 | TNF- $\alpha$ | TOR Infectious Disease Information:

http://www.cdc.gov/ncidod/diseases/index.htm $\mathrm{Q}$ fever $\mid$ SARS

\section{FURTHER INFORMATION}

Karla Kirkegaard's laboratory:

http://cmgm.stanford.edu/micro/kirkegaard_lab/

Access to this interactive links box is free online. 